\title{
Nanoscale
}

Check for updates

Cite this: Nanoscale, 2021, 13, 8976

\section{The $\mathrm{TiO}_{2}-\mu$ implant residual is more toxic than the $\mathrm{Al}_{2} \mathrm{O}_{3}-\mathrm{n}$ implant residual via blocking LAP and inducing macrophage polarization $\dagger$}

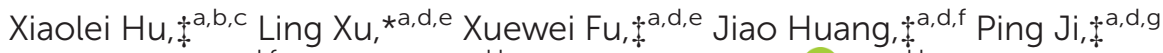 \\ Zhiwei Zhang, ${ }^{a, d, f}$ Feng Deng ${ }^{a, d, b}$ and Xiaomian Wu (D)* * d, d, b
}

Medical device residuals cause harmful effects and diseases in the human body, such as Particle Disease (PD), but the biological interaction of different types of particles is unclear. In this study, after a biological interaction screen between different particles, we aimed to explore the mechanism of the biological interaction between different types of particles, and the effect of a proteasome inhibitor on PD. Our studies showed that the titanium oxide microscale particle $(\mathrm{Ti}-\mu)$ was more toxic than the aluminum oxide nanoscale particle (Al-n). Al-n activated LAP, attenuated the macrophage M1 polarization, inhibited the activator of the NF-кB pathway, and blocked the secretion of inflammatory factors and apoptosis in vitro, and also prevented the inflammation tissue disorder and aseptic loosening in vivo induced by $\mathrm{Ti}-\mu$. What is more, Bortezomib blocked apoptosis, secretion of inflammatory factors and the activation of the NF- $\mathrm{BB}$ pathway induced by $\mathrm{TiO}_{2}$ micro particles. Al-n-induced autophagy could play the function in the efficient clearance of dying cells by phagocytosis, and serves in dampening M1 polarization-related pro-inflammatory responses. While the Ti alloy medical implant and devices are applied worldwide, the toxicity of $\mathrm{Ti}-\mu$ and its interaction with Al-n could be considered in the implant design, and Bortezomib was a potential therapeutic for PD.

Received 2nd February 2021 Accepted 13th April 2021

DOI: $10.1039 / \mathrm{d} 1 \mathrm{nr} 00696 \mathrm{~g}$ rsc.li/nanoscale patients, especially as the global population continues to age. However, most joint replacements end in loosening in different time-frame longevity. About $75 \%$ cases of joint replacement failure are due to aseptic loosening, and mixed implant residuals play an extremely important role in this process. Titanium alloy, aluminum oxide $\left(\mathrm{Al}_{2} \mathrm{O}_{3}\right)$, and polymethyl methacrylate (PMMA) are now widely used in implant materials, materials for drug delivery, composite biomaterials, and tissue engineering. ${ }^{1,2}$ The recent application of these materials as biomaterials was inevitable, considering their outstanding mechanical property. ${ }^{1-4}$ However, the particles produced during their use could lead to irreversible aseptic loosening via participating in the initiation and development of osteolysis around the prosthesis. ${ }^{5}$

Both direct and indirect mechanisms of the granuleinduced osteolysis may involve aggravation of periprosthetic bone resorption with the production of pro-inflammatory cytokines. Most metal wear debris, once it is engulfed by macrophages in the canonical phagocytosis process, would trigger the initiation of inflammation and activate the $\mathrm{T}$ cell-mediated immune response. ${ }^{6}$ There is no clear consensus about which types of wear particles are more toxic, especially in the micro or nano scale, but there is a basic consensus that metal fragments are more proinflammatory in one's body than polymer fragments and ceramic fragments. ${ }^{7,8}$ 
Homeostasis of the bone is under the control of a balance between bone resorption by osteoclasts and bone formation by osteoblasts. $^{9-11}$ Different kinds of particles could evoke the expression of inflammatory cytokines from different signaling pathways. ${ }^{12-14}$ It has been reported that particles, such as titanium alloy, PMMA and polyethylene (PE), could give rise to inflammatory osteolysis primarily via the activation of the nuclear factor kappa-B (NF-кB) and mitogen-activated protein kinase (MAPK) pathways, which are vital for the differentiation and maturation of osteoclast precursors (monocytes or macrophages). ${ }^{14,15}$ PMMA particles initiated an intense inflammatory reaction by macrophages, and enhanced the formation and activity of osteoclast via activating the NF- $\mathrm{BB}$ signal pathway. Compared with the proinflammatory induction by titanium granule, the expression of Toll-like receptors (TLRs), intracellular adapters and osteolytic cytokines induced by ceramic particles in macrophages was lower. Meanwhile, the osteolysis induced in the skull was also lower. ${ }^{16}$ For example, titanium alloy particles could stimulate inflammation, such as tumor necrosis fact-alpha (TNF- $\alpha$ ) and interleukin 1 beta (IL- $\beta$ ) expression in tissues around the aseptic loosening prosthesis. ${ }^{17}$ What is more, TNF- $\alpha$ (rather than IL-1 $\beta$ ) showed a stronger effect on the induction of macrophage M1 polarization. ${ }^{18,19}$ However, the biological interaction of different particle is unclear.

The ubiquitin-proteasome system is vital for the activation of the NF- $\mathrm{KB}$ pathway, and in this process, the ubiquitin E3 ligase is needed. Beta-transducin repeat-containing proteins ( $\beta$-TRCP), as an ubiquitin E3 ligase, is an important positive regulator of the NF- $\kappa \mathrm{B}$ pathway, while cylindromatosis (CYLD), as a deubiquitinase, is a negative regulator of the NF$\kappa \mathrm{B}$ signaling pathway. ${ }^{20-22}$ Our primary study reported that $\beta$-TRCP induced CYLD degradation in the RAW264.7 mouse leukemic monocyte macrophage cell line, which was the negative regulator of the nuclear factor- $\kappa \mathrm{B}$ ligand (RANKL) pathway, and took part in osteoclast differentiation. ${ }^{21}$ Many molecular processes involved in the biochemical and biological defenses are related to the NF- $\mathrm{B}$ pathway. ${ }^{13,23-25}$ It was reported that the omega-3 (v3) fatty acid, docosahexaenoic acid (DHA), suppressed inflammasome activation by inhibiting the nuclear translocation of NF- $\mathrm{B}$, which limited inflammasome activity in bone marrow-derived macrophages (BMDMs). ${ }^{23}$ What is more, there was a direct depression of transcription factor NF$\kappa \mathrm{B}$ with increased caspase 3 , which was an important regulator of apoptosis and cell death. ${ }^{26}$

As a potential regulator of inflammation, LC3-associated phagocytosis (LAP) is a novel pathway of non-canonical autophagy and an autophagosome-independent process, which utilizes components of the canonical autophagy machinery in phagosome membranes. ${ }^{27,28} \mathrm{LAP}$ is able to attenuate autoimmunity via dampening of pro-inflammatory signals upon engulfment of dying cells and prevention of autoantigen presentation to other immune cells. ${ }^{27-29}$ Animals deficient in the LAP pathway have a propensity to develop autoimmunity. ${ }^{30}$ Recently, it was reported that in the macrophage cell line RAW264.7, inhibition of autophagy significantly promoted the

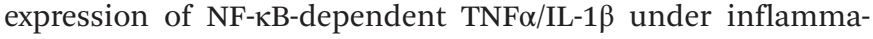
tory stimulation. ${ }^{31}$

Unfortunately, limited nonoperative treatment is available for inflammation and aseptic loosening caused by PD. So far, the effective treatment for granular-induced osteolysis is limited to surgical revision. So, on the one hand, a further understanding of the biological interactions between different particles and a well-designed implant are a vital strategy to prevent PD. On the other hand, identifying drugs that inhibit granule-induced osteolysis remains a major challenge. Targeting the activity of $\mathrm{NF}-\mathrm{\kappa B}$ could be a potential tactic to rescue osteolysis in macrophages, in which NF-kB signaling could be activated by wear particles. ${ }^{8,32}$ The proteasome inhibitor Bortezomib (BTZ) is the first approved proteasome inhibitor by FDA for clinical application, and it has been tested as a treatment for inflammation. ${ }^{8,22,33,34}$ At a low dose $(<0.5 \mathrm{nM})$, it does not induce cell apoptosis, but prevents cell apoptosis. Our previous study had also proved this dosedependent manner of BTZ in the treatment of periodontal disease. Therefore, we used macrophages in vitro and a mouse calvarial model in vivo to evaluate the effect of LAP and BTZ on the prevention of inflammation and aseptic loosening induced by different particles and the biological interaction between different particles, especially titanium alloy and aluminum particle.

\section{Materials and methods}

\subsection{Particle characterization}

Commercially pure particles were obtained from SigmaAldrich and from Mitsui Chemicals. They were labeled as follows in this study. Ti- $\mu$ : Titanium oxide microparticle $\left(\mathrm{TiO}_{2}\right.$, \#224227, Sigma-Aldrich); Ti-n: Titanium oxide nanoparticle, $\left(\mathrm{TiO}_{2}, \# 718647\right.$, Sigma-Aldrich); Al- $\mu$ : Alumium oxide microparticle $\left(\mathrm{Al}_{2} \mathrm{O}_{3}, \# 265497\right.$, Sigma-Aldrich); Al-n: Aluminum oxide nanoparticle $\left(\mathrm{Al}_{2} \mathrm{O}_{3}, \# 544833\right.$, Sigma-Aldrich); P-s: Ultra-high Molecular Weight Polyethylene (UHMWPE) particle (\#434272, Sigma-Aldrich) and P-l: UHMWPE particle (\#340 M, Mitsui Chemicals). The samples were sterilized by $\gamma$-ray (Zhongjin Irradiation Chengdu Co., Ltd), as described in our previous study. ${ }^{1,8}$

Transmission electron microscopy (TEM) measurements were performed to characterize the particles. The particles were suspended in ultrapure water by ultrasonic vibration, transferred to the copper mesh stage, dried overnight and observed by a TEM (Hitachi 7500) at $80 \mathrm{keV}$.

Fourier-transform infrared (FT-IR) spectroscopy analysis was performed with a FT-IR Spectrometer (Thermo Fisher Scientific, Madison, USA). The FTIR spectra of Ti- $\mu$, Ti-n, Al- $\mu$, Al-n, P-l and P-s were collected from 4000 to $400 \mathrm{~cm}^{-1}$ with a resolution of $0.5 \mathrm{~cm}^{-1}$ using the $\mathrm{KBr}$ disk technique.

\subsection{Cell culture}

The RAW 264.7 mouse monocyte/macrophages cell line was obtained from the Shanghai Institute of Cell Biology (Chinese 
Academy of Sciences, Shanghai, China). RAW 264.7 cells were incubated at $37{ }^{\circ} \mathrm{C}$ in a humidified atmosphere $\left(5 \% \mathrm{CO}_{2}, 95 \%\right.$ air) in $\alpha$-DMEM (Thermo Fisher, DMEM, High Glucose, HEPES, no. 12430062) consisting of $10 \%$ (v/v) fetal bovine serum (Natocor, SFBE) and antibiotics gained from Beyotime Biotechnology (Jiangsu, China).

\subsection{Flow cytometry}

The flow cytometry assay was performed with an Apoptosis and Necrosis Assay Kit (C1056, Beyotime Biotechnology, Shanghai, China), which contained Hoechst and propidium iodide (PI) for double-color detection method. In brief, RAW264.7 cells $\left(5 \times 10^{4}\right.$ cells per $\left.\mathrm{ml}\right)$ were treated with different concentrations of pure or a mix of different kinds of particles for $72 \mathrm{~h}$ for bio-activity screens. The screens are Screen A: Ti- $\mu(5 \mu \mathrm{m})$ and Al-n (50 nm), Screen B: Ti-n (21 nm) and Al- $\mu(10 \mu \mathrm{m})$, Screen C: Ti-n (21 nm) and Al-n (50 nm), Screen D: Ti- $\mu(5 \mu \mathrm{m})$ and Al- $\mu(10 \mu \mathrm{m})$, Screen E: Ti-n $(21 \mathrm{~nm})$ and P-l $(155 \mu \mathrm{m})$, Screen F:Ti-n $(21 \mathrm{~nm})$ and P-s $(40-48 \mu \mathrm{m})$, Screen G: Ti- $\mu(5 \mu \mathrm{m})$ and P-l $(155 \mu \mathrm{m})$, and Screen H: Ti- $\mu$ $(5 \mu \mathrm{m})$ and P-s $(40-48 \mu \mathrm{m})$.

Screen A groups: Control, Ti- $\mu$ 10, Ti- $\mu$ 50, Ti- $\mu 10+0.5 \mathrm{nM}$ BTZ, Al-n 10, Al-n 50, Al-n $10+0.5$ nM BTZ, Ti- $\mu+$ Al-n 10 (3:1), Ti- $\mu$ + Al-n 10 (1:1), Ti- $\mu$ + Al-n 10 (1:3), Ti- $\mu$ + Al-n 20 (1:1), Ti- $\mu$ + Al-n $20(1: 1)+0.5$ nM BTZ; Screen B groups: Control, Ti-n 10, Ti-n $10+0.5$ nM BTZ, Ti-n + Al- $\mu 10$ (1:1), Ti- $\mu$ + Al-n $10(1: 1)+0.5$ nM BTZ, Ti-n + Al- $\mu 20$ (1:1), Ti- $\mu+$ Al-n 20 (1:1) + 0.5 nM BTZ; Screen C groups: Control, Ti-n 10, Ti-n $10+0.5$ nM BTZ, Al-n 10, Al-n $10+0.5$ nM BTZ, Ti-n + Aln 20 (1:1), Ti- $\mu$ + Al-n $20(1: 1)+0.5$ nM BTZ, Ti-n + Al-n 10 (1:1), Ti- $\mu$ + Al-n $10(1: 1)+0.5$ nM BTZ; Screen D groups: Control, Ti- $\mu$ 10, Ti- $\mu 10+0.5$ nM BTZ, Ti-n + Al- $\mu 10$ (1:1), Ti- $\mu$ + Al-n $10(1: 1)+0.5$ nM BTZ, Ti-n + Al- $\mu 20$ (1:1), Ti- $\mu$ + Al-n 20 (1:1) + 0.5 nM BTZ; Screen E groups: Control, Ti-n 50, P-l 50, Ti-n 10, P-l 10, Ti-n $10+0.5$ nM BTZ, P-1 $10+0.5$ nM BTZ, Ti-n + P-l $10(1: 1)+0.5$ nM BTZ, Ti-n + P-l $20(1: 1)+$ 0.5 nM BTZ, Ti-n + P-l 20 (1:1), Ti-n + P-l 10 (3:1), Ti-n + P-1 10 (1:1), Ti-n + P-l 10 (1:3); Screen F groups: Control, Ti-n 50, P-s 50, Ti-n 10, P-s 10, Ti-n $10+0.5$ nM BTZ, P-s $10+0.5$ nM BTZ, Ti-n + P-s $10(1: 1)+0.5$ nM BTZ, Ti-n + P-s $20(1: 1)+0.5$ nM BTZ, Ti-n + P-s 20 (1:1), Ti-n + P-s 10 (3:1), Ti-n + P-s 10 (1:1), Ti-n + P-s 10 (1:3); Screen G groups: Control, Ti- $\mu$ 10, P-1 10, Ti- $\mu 10+0.5$ nM BTZ, P-1 $10+0.5$ nM BTZ, Ti- $\mu$ 50, P-1 50, Ti- $\mu$ + P-1 $20(1: 1)+0.5$ nM BTZ, Ti- $\mu$ + P-1 20 (1:1), Ti- $\mu$ + P-1 10 (3:1), Ti- $\mu$ P-l 10 (1:1), Ti- $\mu$ + P-l 10 (1:3), Ti- $\mu$ + P-l 10 $(1: 1)+0.5$ nM BTZ; Screen H groups: Control, Ti- $\mu$ 10, P-s 10, Ti- $\mu$ 50, P-s 50, Ti- $\mu 10+0.5$ nM BTZ, P-s $10+0.5$ nM BTZ, Ti- $\mu$ + P-s 10 (3:1), Ti- $\mu$ + P-s 10 (1:1), Ti- $\mu$ + P-s 10 (1:3), Ti- $\mu$ + P-s $10(1: 1)+0.5$ nM BTZ, Ti- $\mu$ + P-s $20(1: 1), \mathrm{Ti}-\mu$ + P-s $20(1: 1)+$ $0.5 \mathrm{nM}$ BTZ. $\left(\mu \mathrm{g} \mathrm{ml} \mathrm{ml}^{-1}\right)$.

After stimulation by particles for $72 \mathrm{~h}$ in 6-well plates, the cells were washed twice with PBS (Phosphate buffered saline) to remove the co-cultured particles and trypsinized. The cells were washed twice again with PBS, suspended in a centrifugal tube and mixed with $5 \mu \mathrm{l}$ Hoechst 33342 staining solution and $5 \mu \mathrm{l}$ propidium iodide (PI) staining solution. The cells were incubated at $4{ }^{\circ} \mathrm{C}$ for 30 minutes in the dark. Red and blue fluorescence were detected by flow cytometry.

\subsection{Cell viability}

Cells were treated with different concentrations of pure or a mix of $\mathrm{Ti}-\mu(5 \mu \mathrm{m})$ and Al-n $(50 \mathrm{~nm})$ particles for $72 \mathrm{~h}$. Groups are the Control, Ti- $\mu 10 \mu \mathrm{g} \mathrm{ml}{ }^{-1}$, Ti- $\mu 10 \mu \mathrm{g} / \mathrm{ml}+0.5 \mathrm{nM} \mathrm{BTZ}$, Al-n $10 \mu \mathrm{g} \mathrm{ml} \mathrm{m}^{-1}$, Al-n $10 \mu \mathrm{g} / \mathrm{ml}+0.5 \mathrm{nM} \mathrm{BTZ,} \mathrm{Ti- \mu} \mathrm{+} \mathrm{Al-n}$ $10 \mu \mathrm{g} \mathrm{ml}^{-1}$ (1:1), Ti- $\mu$ Al-n $10 \mu \mathrm{g} \mathrm{ml}^{-1}(1: 1)+0.5 \mathrm{nM} \mathrm{BTZ}$, $\mathrm{Ti}-\mu+\mathrm{Al}-\mathrm{n} 20 \mu \mathrm{g} \mathrm{ml}{ }^{-1}(1: 1), \mathrm{Ti}-\mu+\mathrm{Al}-\mathrm{n} 20 \mu \mathrm{g} \mathrm{ml}^{-1}(1: 1)+$ $0.5 \mathrm{nM}$ BTZ. Then, the cells were incubated at $37{ }^{\circ} \mathrm{C}$ with $0.5 \mathrm{mg} \mathrm{ml}^{-1}$ MTT for $4 \mathrm{~h}$. To dissolve the formazan crystals, dimethyl sulfoxide was added in the culture medium. The supernatant of each sample after centrifugation was transferred to 96-well plates for $4 \mathrm{~h}$. Then, a micro plate reader was used to measure the corresponding absorbance at a wavelength of $570 \mathrm{~nm}$. Bortezomib (PS-341) was purchased from Selleck Chemicals (Houston, TX, USA), and stored at a concentration of $1 \mathrm{M}$ in sterile saline solution at $-80{ }^{\circ} \mathrm{C}$.

\subsection{Cellular immunofluorescence}

Laser confocal plates were soaked in PBS, and then fixed in $4 \%$ paraformaldehyde. They were then soaked in PBS with $0.5 \%$ Triton X-100 at room temperature for 20 minutes, dried and sealed, and then incubated overnight at $4{ }^{\circ} \mathrm{C}$ with the first antibody LC3B. Subsequently, they were incubated with the fluorescent second antibody by dripping with DAPI for 5 minutes, and then the nucleus was stained. The liquid seal of the anti-fluorescence quenching agent was then observed under a fluorescence microscope.

\subsection{RT-PCR analysis}

RAW 264.7 cell samples were challenged with particles ( $\mathrm{Ti}-\mu$ $(5 \mu \mathrm{m})$ and Al-n $(50 \mathrm{~nm}))$ and/or $0.5 \mathrm{nM}$ BTZ in a six-well plate for $72 \mathrm{~h}$. The total RNA was isolated by total mRNA extraction kit (Tiangen Biotechnology, Beijing, China), according to the manufacturer's instructions and reverse transcribed to cDNA. Subsequently, cDNA was used for real time quantitative PCR performed with a RT-PCR kit (Tiangen Biotechnology, Beijing, China) on the CFX Connect PCR instrument (BIO-RAD, USA). Relative expression values of the target gene were analyzed, and the housekeeping gene was used as a quantitative control for the RNA level. PCR primers (TNF $\alpha$ F: TGTCTCAGCCTCTTCTCATTCCT, TNF $\alpha$ R: GGTTTGCTACGACGTGGGCTACAG; $\beta$-actin F:GTGGGCCGCCCTAGGCACCAG, $\beta$-actin R:CTCTTTGATGTCACGCACGATTTC) were synthesized at Sanon Biotechnology (Shanghai, China).

\subsection{Western blotting analysis}

After stimulation ( $\mathrm{Ti}-\mu(5 \mu \mathrm{m})$ and Al-n $(50 \mathrm{~nm}))$, lysates were lysed in cold RIPA buffer with protease inhibitors (Beyotime, Shanghai, China) to extract proteins. Then, the lysates were centrifuged at $4{ }^{\circ} \mathrm{C}$ and boiled. The protein concentration in the lysates from each sample was detected with a BCA Protein Assay Kit (Beyotime Biotechnology, P0012). Equal amounts of protein extracted $(25 \mu \mathrm{g})$ were separated by gel electrophoresis 
(Beyotime Biotechnology, Jiangsu, China), and then shifted onto a polyvinylidene difluoride (PVDF) membrane (Amersham Hybond, A10083114). After incubating with antibodies, the membranes were developed with the enhanced chemiluminescence (ECL) detection kit (Thermo, 34096). At last, the semi-quantitative analysis was performed using the National Institutes of Health (NIH) Image J.

\subsection{Mouse model of the particle-induced aseptic bone loosening}

We established a mouse calvarial osteolysis model, as previously reported, to detect the effect of $\mathrm{Al}_{2} \mathrm{O}_{3}$ and BTZ on osteolysis induced by Ti particles. ${ }^{8,35}$ All animal experiments were strictly conducted in accordance with guidelines and procedures authorized by the Animal Care and Use Committee of Chongqing Medical University. Briefly, 25 healthy C57BL/ 6 mice (male, 6-8 weeks old, 19-23 g) were randomly divided into five groups ( 5 animals per group): Control group, Ti- $\mu$ particle group, Al-n particles group, Ti- $\mu+\mathrm{Al}-\mathrm{n}$ particles group, Ti$\mu+$ Al-n particles + BTZ administrated group. After abdominal anesthesia by $3 \%$ pentobarbital sodium, the hair was shaved and a $1 \mathrm{~cm}$ length incision was made along the mid-line by sharp dissection, and the periosteum over the calvarium was exposed. With blunt separation of the cranial periosteum, the surface of the cranial bones was exposed. Using a periosteal elevator and hemostatic forceps, a $1 \mathrm{~cm} \times 1 \mathrm{~cm}$ area around the mid-line crossing the front and bregma bone in the cranium of the mouse was obtained in every mouse, as the schematic diagram of the animal models shown (ESI, Fig. $1 \dagger$ ). In the $\mathrm{Ti}-\mu$ particle group, $10 \mathrm{mg} \mathrm{TiO}_{2}$ particles were embedded around the middle suture. In the Al-n particles group, $10 \mathrm{mg} \mathrm{Al}_{2} \mathrm{O}_{3}$ particles were embedded around the middle suture. In the $\mathrm{Ti}-\mu+\mathrm{Al}-\mathrm{n}$ particles group and $\mathrm{Ti}-\mu+\mathrm{Al}-\mathrm{n}$ particles + BTZ groups, $5 \mathrm{mg} \mathrm{TiO}_{2}$ particles and $5 \mathrm{mg} \mathrm{Al}_{2} \mathrm{O}_{3}$ particles were embedded around the middle suture. For the mixture group, the particles were mixed by a vortex for 30 seconds. Particles were embedded on the surface of the bone at the middle calvaria suture before closing the incision. In the control group, the same surgery was performed in mice just without particle embedding. Two days after inserting the particles for the control and experimental groups, the mice were locally subcutaneously injected with PBS or/and the safe concentration ( $0.1 \mathrm{nM})$ of BTZ. The injections were at each middle point of the edges of the surgical square area to make sure the drug covered the whole surgical area (three injections per week). The animal experiment lasted 14 days, according to our previous study. ${ }^{8,30,53}$

At the fixed time, all mice were executed. Specimens of the skull in each group were scanned using micro-CT. Subsequently, a region of interest (ROI) of $1.5 \times 1.5 \mathrm{~mm}$ in the surgical area was selected, and the trabecular thickness (Th), trabecular spacing (SP) and bone volume/total volume (BV/TV) of each sample were calculated for quantitative analysis. In the surgical area, the soft tissue was harvested, fixed, dehydrated, embedded in paraffin and stored at $20{ }^{\circ} \mathrm{C}$. The paraffin specimens were sliced horizontally to obtain 7 micron thick sections. Then, the sections were treated with hematoxylin-eosin (HE), and the expression of Casepase-3, IL-6, RANKL and others in the tissue sections were analyzed by immunohistochemical staining.

\subsection{Statistical analysis}

Statistical analyses were performed by the one-way analysis of variance (One-way ANOVA). The data were expressed as the mean \pm S.D., and a value of $p<0.05$ or $p<0.01$ was considered statistically significant in this study.

\section{Results}

\subsection{Particle characterization}

As shown in Fig. 1, the Ti- $\mu$, Ti-n, Al- $\mu$, Al-n, and P-s particles were observed by TEM (Fig. 1A1-A4 and A6) and P-l was photographed with an optical microscope (A5). The sizes of the particles are shown in Fig. 1A; Ti- $\mu$ was $5 \mu \mathrm{m}$, Ti-n was $21 \mathrm{~nm}, \mathrm{Al}-\mu$ was $10 \mu \mathrm{m}$, Al-n was $50 \mathrm{~nm}$, P-l was $155 \mu \mathrm{m}$ and P-s was from $40 \mu \mathrm{m}$ to $48 \mu \mathrm{m}$.

The FT-IR result showed that lattice vibrations of 830 and $920 \mathrm{~cm}^{-1}$ were detected in the $\mathrm{TiO}_{2}$ particles (Fig. 1B1 and B2); an absorption band at $500-900 \mathrm{~cm}^{-1}$ without any fine structure could be the characteristic infrared spectrum of $\mathrm{Al}_{2} \mathrm{O}_{3}$ (Fig. 1B3 and B4); the peaks at $2920 \mathrm{~cm}^{-1}$ and $2850 \mathrm{~cm}^{-1}$ of the UHMWPE correspond to the asymmetric and symmetric stretching modes of $\mathrm{C}-\mathrm{H}$, respectively, while the peak at $1470 \mathrm{~cm}^{-1}$ is related to the in-plane bending vibration of $\mathrm{C}-\mathrm{H}$, and the $730 \mathrm{~cm}^{-1}$ represented the methylene rocking vibrations (Fig. 1B5 and B6), and these characteristic bands of the particles agreed with previous studies. ${ }^{36-38}$

\subsection{Ti- $\mu$ showed a more severe cytotoxicity than Al-n in flow cytometry experiment}

In order to further understand the biological interaction of the different particles, we performed biological screens of the cell reaction after the macrophage cells were exposed to different pure or mixed particles. While Hoechst 33342 could penetrate the cell membrane, the fluorescence of the apoptotic cells was higher than that of the normal cells due to chromatin condensing when apoptosis occurs. PI could not penetrate the cell membrane, and could not stain normal or apoptotic cells with intact cell membranes. However, PI could stain necrotic cells, in which the integrity of the cell membrane was lost.

As shown in the flow cytometry results (Fig. 2A and ESI Fig. $2 \dagger$ ), $\mathrm{TiO}_{2}$ and UHMWPE were more toxic than the $\mathrm{Al}_{2} \mathrm{O}_{3}$ particles. After $\mathrm{TiO}_{2}$ particles were mixed with UHMWPE particles (ESI Fig. $2 \dagger$ ), the rates of apoptosis and necrotic cells decreased significantly. BTZ and $\mathrm{Al}_{2} \mathrm{O}_{3}$ could effectively inhibit the cell apoptosis and necrosis induced by $\mathrm{TiO}_{2}$ particles (Fig. 2A-D). The apoptotic and necrosis rates of the cells exposed to Ti- $\mu$ decreased after being co-cultured with Al-n granules (Fig. 2A and E), and further decreased after BTZ administration. When they were treated with BTZ at a low dose (0.5 nM), the drop of the apoptotic and necrosis rates in the Ti- $\mu$ group was more obvious than that in the Al-n group, 

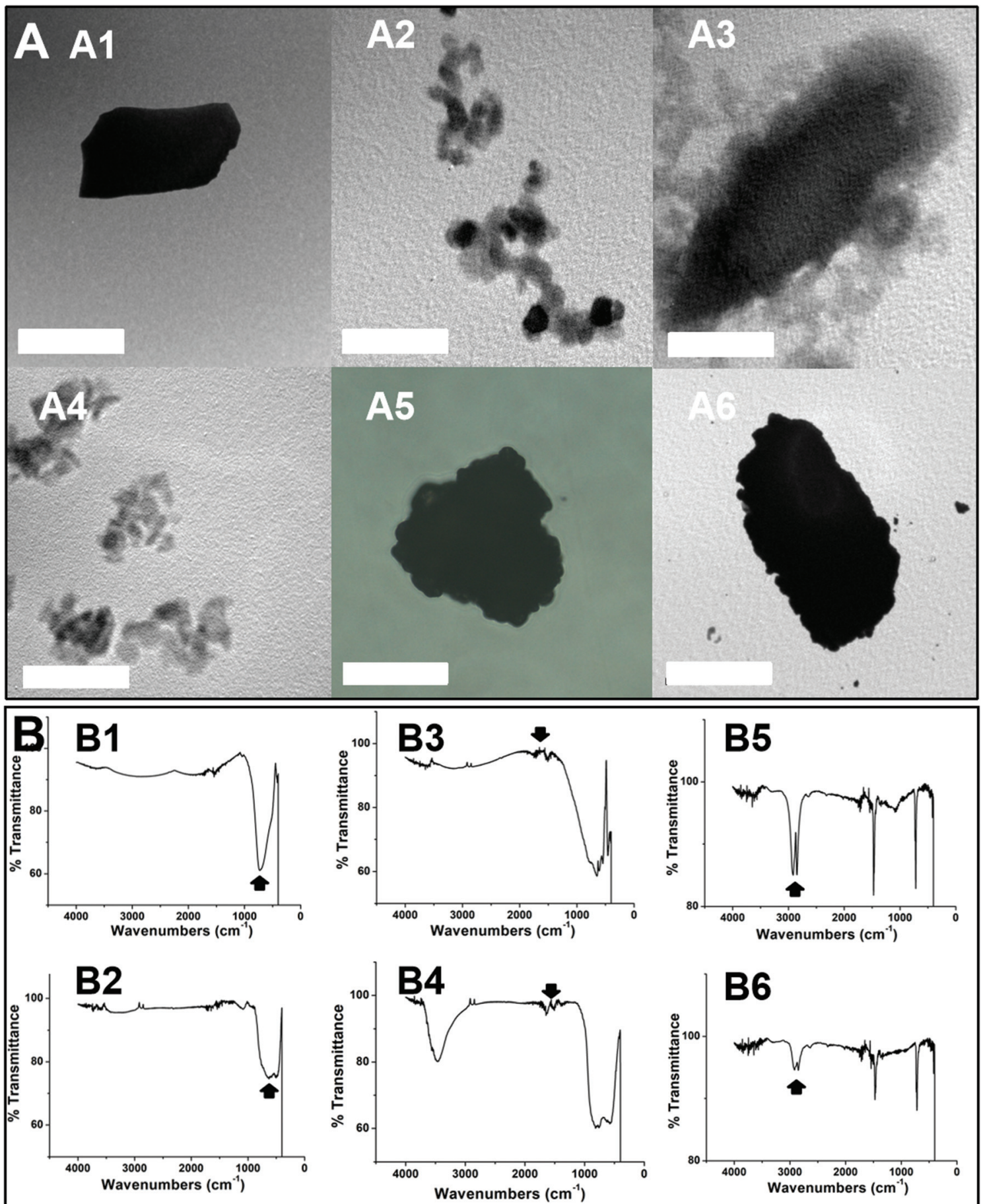

Fig. 1 Particle characterization. A: The Ti- $\mu$ (Titanium oxide $\left(\mathrm{TiO}_{2}\right)$ microparticle), Ti-n (Titanium oxide $\left(\mathrm{TiO}_{2}\right)$ nanoparticle), Al- $\mu$ (Alumium oxide $\left(\mathrm{Al}_{2} \mathrm{O}_{3}\right)$ microparticle), Al-n (Aluminum oxide $\left(\mathrm{Al}_{2} \mathrm{O}_{3}\right)$ nanoparticle), P-s (Ultra-high Molecular Weight Polyethylene (UHMWPE)) particles were observed by TEM (A1-A4, and A6) and P-l: UHMWPE was photographed with an optical microscope (A5). (A1: bar = $5 \mu \mathrm{m} ; \mathrm{A} 2$ and A4: bar = 100 nm; $A 3$ : bar $=200 \mathrm{~nm} ; A 5:$ bar $=100 \mu \mathrm{m}$ and A6: bar $=10 \mu \mathrm{m})$. B: Fourier transform infrared spectroscopy (FTIS) results of different particles are shown in B1 (Ti- $\mu), B 2(T i-n), B 3(A l-\mu), B 4(A l-n), B 5(P-l)$ and B6 (P-s). The FTIR spectra were collected from 4000 to $400 \mathrm{~cm}^{-1}$ with a resolution of $0.5 \mathrm{~cm}^{-1}$. The characteristic infrared spectrum of $\mathrm{TiO}_{2}$ could be found at $830 \mathrm{~cm}^{-1}$ and $920 \mathrm{~cm}^{-1}$, an absorption band at $500-900 \mathrm{~cm}^{-1}$ for $\mathrm{Al}_{2} \mathrm{O}_{3}$ and peaks at $2920 \mathrm{~cm}^{-1}$ and $2850 \mathrm{~cm}^{-1}$ for UHMWPE.

which indicated better biocompatibility in the Al-n group (Fig. 2A and C). What is more, the apoptotic and necrosis rate induced by $\mathrm{TiO}_{2}$ was more obviously reduced by Al-n (Fig. 2A and C) than Al- $\mu$ (Fig. 2B and D). So, we detected the biological effect of Al-n on Ti- $\mu$ in the following assays in order to offer solid data for implant design. 

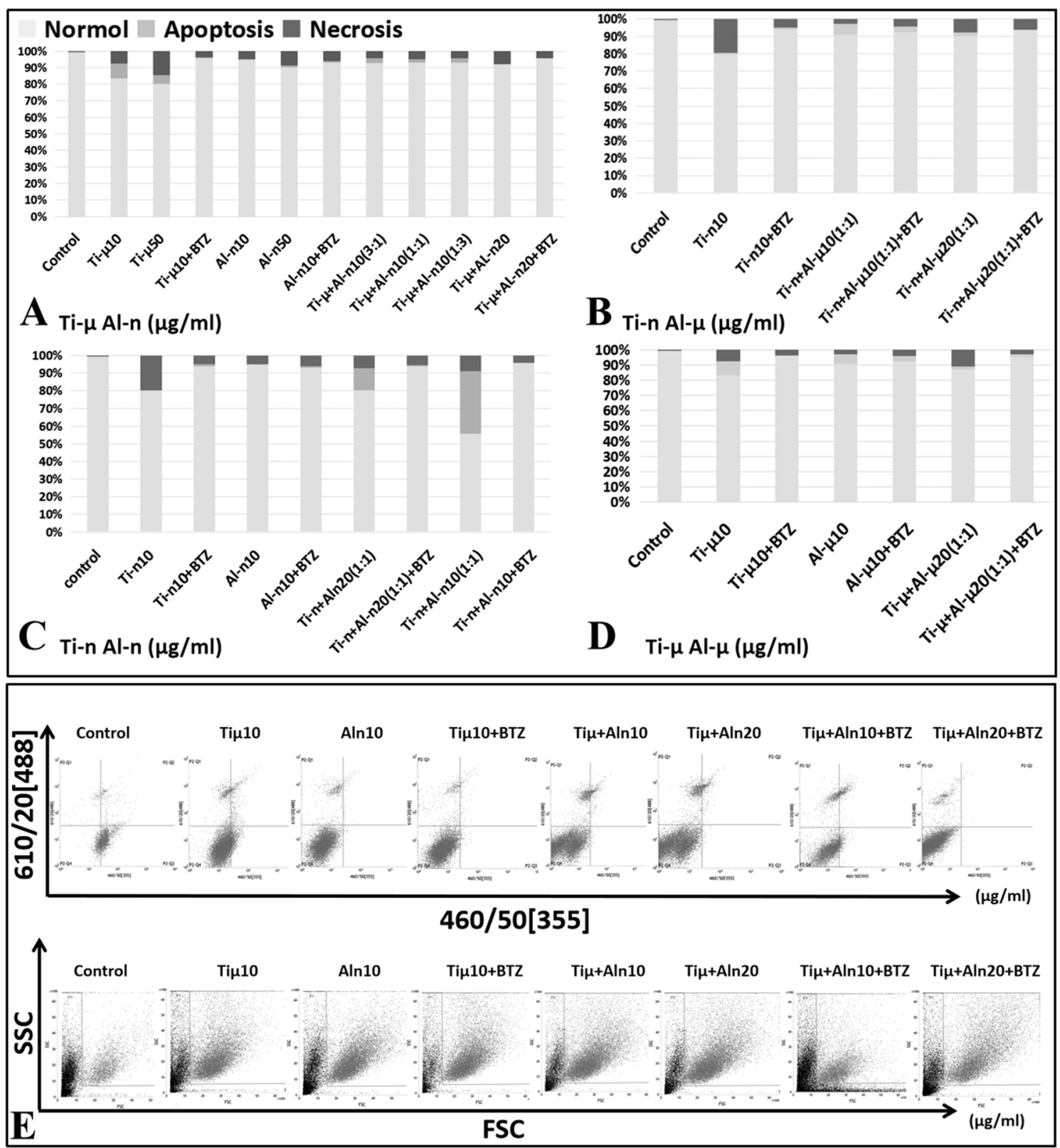

Fig. $2 \mathrm{Ti}-\mu$ showed more severe cytotoxicity than Al-n in the flow cytometry experiment. A-D: The biological screens of the proportion of normal, apoptosis, and necrosis cells after co-culturing with or without Ti, Al particles and $0.5 \mu \mathrm{mol} \mathrm{ml}^{-1} \mathrm{BTZ}$ for 3 days in a flow cytometry assay. (Ti- $\mu$ : $5 \mu \mathrm{m}$; Ti-n: $21 \mathrm{~nm}$; Al- $\mu$ : $10 \mu \mathrm{m}$; Al-n: $50 \mathrm{~nm}$ ). E: Apoptosis and necrosis of RAW264.7 cells after co-culturing with or without Ti- $\mu$, Al-n and $0.5 \mu \mathrm{mol}$ $\mathrm{ml}^{-1}$ BTZ for 3 days in a flow cytometry assay. (Ti- $\mu 10\left(10 \mu \mathrm{g} \mathrm{ml}^{-1}\right.$ of Ti- $\mu$ particles), Al-n10 (10 $\mu \mathrm{g} \mathrm{ml}^{-1}$ of Al-n particles), Ti- $\mu+\mathrm{Al}-\mathrm{n} 10\left(10 \mu \mathrm{g} \mathrm{ml} \mathrm{H}^{-1}\right.$ of Ti- $\mu$ mixed with Al-n, Ti- $\mu$ : Al-n = 1:1) and Ti- $\mu$ + Al-n $20\left(20 \mu \mathrm{g} \mathrm{ml}^{-1}\right.$ of Ti- $\mu$ mixed with Al-n, Ti- $\left.\mu: \mathrm{Al}-\mathrm{n}=1: 1\right)$ with or without BTZ $\left.\left(0.5 \mathrm{nmol}^{-1} \mathrm{ml}^{-1}\right)\right)$.

3.3 The decreased cell viability induced by Ti- $\mu$ could be prevented by Al-n and BTZ

In order to detect the effect of BTZ and the interaction of different particles on cell viability, we took pictures in a light microscope and performed the MTT test. Fig. 3 and ESI Fig. $2 \dagger$ showed that the cell viability of macrophage RAW264.7 after exposure to particles declined slightly in all $\mathrm{TiO}_{2}$ groups. BTZ and $\mathrm{Al}-\mathrm{n}$ could prevent the toxicity induced by Ti- $\mu$. Light microscopic examination (Fig. 3A) showed that the cell number decreased especially in the Ti- $\mu$ groups. After adding Al-n and/or BTZ to the Ti- $\mu$ groups, the cell number increased significantly. Cells in the Ti- $\mu$ group showed a phagocytosis phenomenon, especially in a high concentration at $50 \mu \mathrm{g} \mathrm{ml} \mathrm{m}^{-1}$ of Ti- $\mu$ (Fig. 3A). At the same time, the cells appeared as fragments of lysis. After being co-cultured with BTZ, the cell viability of RAW264.7 got a significant improvement compared with the groups without BTZ treatment including Ti- $\mu$, Al-n and the mixed group (Fig. 3B) $\left({ }^{*} p<0.05\right)$. While there was a significant difference of cell activity that could be found between the pure 


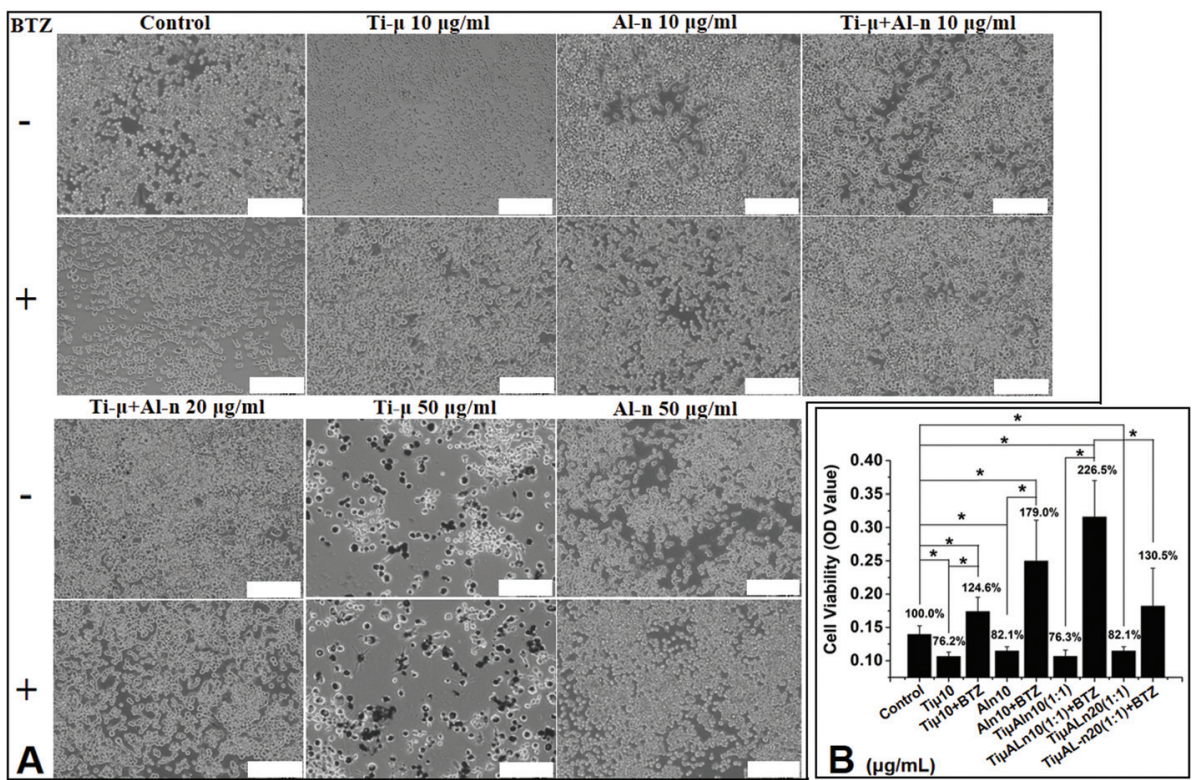

Fig. 3 The decreased cell viability induced by Ti- $\mu$ could be prevented by Al-n and BTZ. A: Cells co-cultured with or without Ti- $\mu$, Al-n particles and

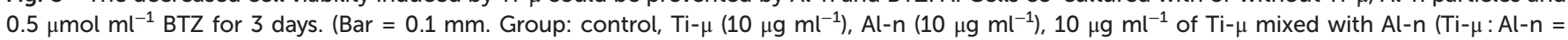
1:1), $20 \mu \mathrm{g} \mathrm{ml}^{-1}$ of Ti- $\mu$ mixed with Al-n (Ti- $\left.\mu: \mathrm{Al}-\mathrm{n}=1: 1\right), \mathrm{Ti}-\mu\left(50 \mu \mathrm{g} \mathrm{ml}^{-1}\right)$ and Al-n $\left(50 \mu \mathrm{g} \mathrm{ml}^{-1}\right)$ with or without $\left.0.5 \mathrm{nmol} \mathrm{ml}^{-1} \mathrm{BTZ}\right)$. (Bar $=$ $200 \mu \mathrm{m})$. B: Cell morphology after co-cultured with or without Ti- $\mu$ or Al-n particles for 3 days (Bar $=0.1 \mathrm{~mm}$. Group: Ti- $\mu 10 \mu \mathrm{g} \mathrm{ml}{ }^{-1}$, Ti- $\mu$ $50 \mu \mathrm{g} \mathrm{ml}^{-1}, \mathrm{Al}-\mathrm{n} 10 \mu \mathrm{g} \mathrm{ml}^{-1}, \mathrm{Al}-\mathrm{n} 50 \mu \mathrm{g} \mathrm{ml}^{-1}$ ). (Bar $\left.=100 \mu \mathrm{m}\right)$.

Ti- $\mu$ and pure Al-n group, this result also indicated that Al-n had lower cytotocixity than the Ti- $\mu$ group.

\subsection{Al-n induced an obvious LC3-associated phagocytosis (LAP) process in the macrophage}

As an important indicator of autophagy, LC-3 could significantly promote the LAP of RAW264.7 cells. We analyzed the LC-3 expression by challenging cells with different sizes of $\mathrm{TiO}_{2}$ and $\mathrm{Al}_{2} \mathrm{O}_{3}$ particles via immunofluorescence assays and western blot (WB) experiments. In immunofluorescence assays, LC-3 expression was higher in the Al-n group and mixture group than the Ti- $\mu$ group and control group (Fig. 4). While the RAW264.7 knockdown and knockout cell lines were too fragile to suffer both drug purification of the cell line and particle stimulation, we utilized BTZ as an inhibitor to block the NF- $\mathrm{kB}$ signaling pathway. The BTZ further increased the LC-3 level in the mixture groups compared with the Ti- $\mu+\mathrm{Al}-\mathrm{n}$ group, but the LC-3 level was still lower than the Al-n group (Fig. 4). These results indicated that both Al-n and BTZ could evoke the expression of LC-3 rather than Ti- $\mu$.

3.5 Al-n particles prevented the macrophage M1 polarizationrelated inflammation via inhibition of the activation of the NF- $\kappa B$ signaling pathway

In order to further explore the effect of $\mathrm{TiO}_{2}$ and $\mathrm{Al}_{2} \mathrm{O}_{3}$ on the macrophage M1 polarization-related inflammation, we performed a mRNA screen of the TNF- $\alpha$ and IL- $1 \beta$ expression of the macrophage under the stimulation of different concentrations of different scale $\mathrm{TiO}_{2}$ and $\mathrm{Al}_{2} \mathrm{O}_{3}$ particles (Fig. 5A and B, ESI Fig. $4 \mathrm{~A}$ and $\mathrm{B} \dagger$ ). The screen results showed that both micro and nano scale particles of Al-n evoked a higher expression level of IL-1 $\beta$ compared with the expression of TNF- $\alpha$ at different concentrations. In contrast, Ti- $\mu$ promoted a higher level of TNF- $\alpha$ expression compared to IL- $1 \beta$. While TNF- $\alpha$ could induce the macrophage for M1 polarization and evoke the inflammation reaction and IL-1 $\beta$ could promote the macrophage M2 polarization, these results indicated that $\mathrm{Al}-\mathrm{n}$ prevented the $\mathrm{Ti}-\mu-$ induced inflammation in a macrophage M1-related manner.

While the expression of TNF- $\alpha$ and IL- $1 \beta$ was under the control of the NF-кB signaling pathway, we detected $\beta$-TRCP, the activator of the NF- $\mathrm{KB}$ signaling pathway, and CYLD, the inhibitor of the NF-kB signaling pathway, under the stimulation of Ti- $\mu$ particles and Al-n particles. In mixture groups (Fig. 5C and ESI Fig. $4 \dagger$ ), the expression of $\beta$-TRCP was elevated by Ti- $\mu$ particles and decreased by Al-n particles in a concentration-dependent manner. However, the whole cell protein level was not significant changed (ESI Fig. $5 \dagger$ ). The expression of TNF- $\alpha$ was also higher in the Ti- $\mu$ group than in the Al-n group. The expression of TNF- $\alpha$ in the mixed group was decreased by the Al-n particle in a concentration-dependent manner (Fig. 5F). While the $\beta$-TRCP knockout and knockdown macrophage cell line was too fragile to suffer both drug purification of cell line and particle stimulation, we again applied BTZ as the NF-KB signaling pathway inhibitor to have a double check of the effect of the NF-kB signaling pathway on the M1 polarization inflammation. Al-n could elevate the expression of IL-1 $\beta$ (Fig. 5E). Both Al-n and BTZ reduced the activity of $\beta$-TRCP increased by Ti- $\mu$ (Fig. $5 \mathrm{~F}$ ). Al-n and BTZ also both prevented mRNA and protein expression of the inflammatory TNF- $\alpha$ (Fig. 5E and F). These results indicated that the biologi- 


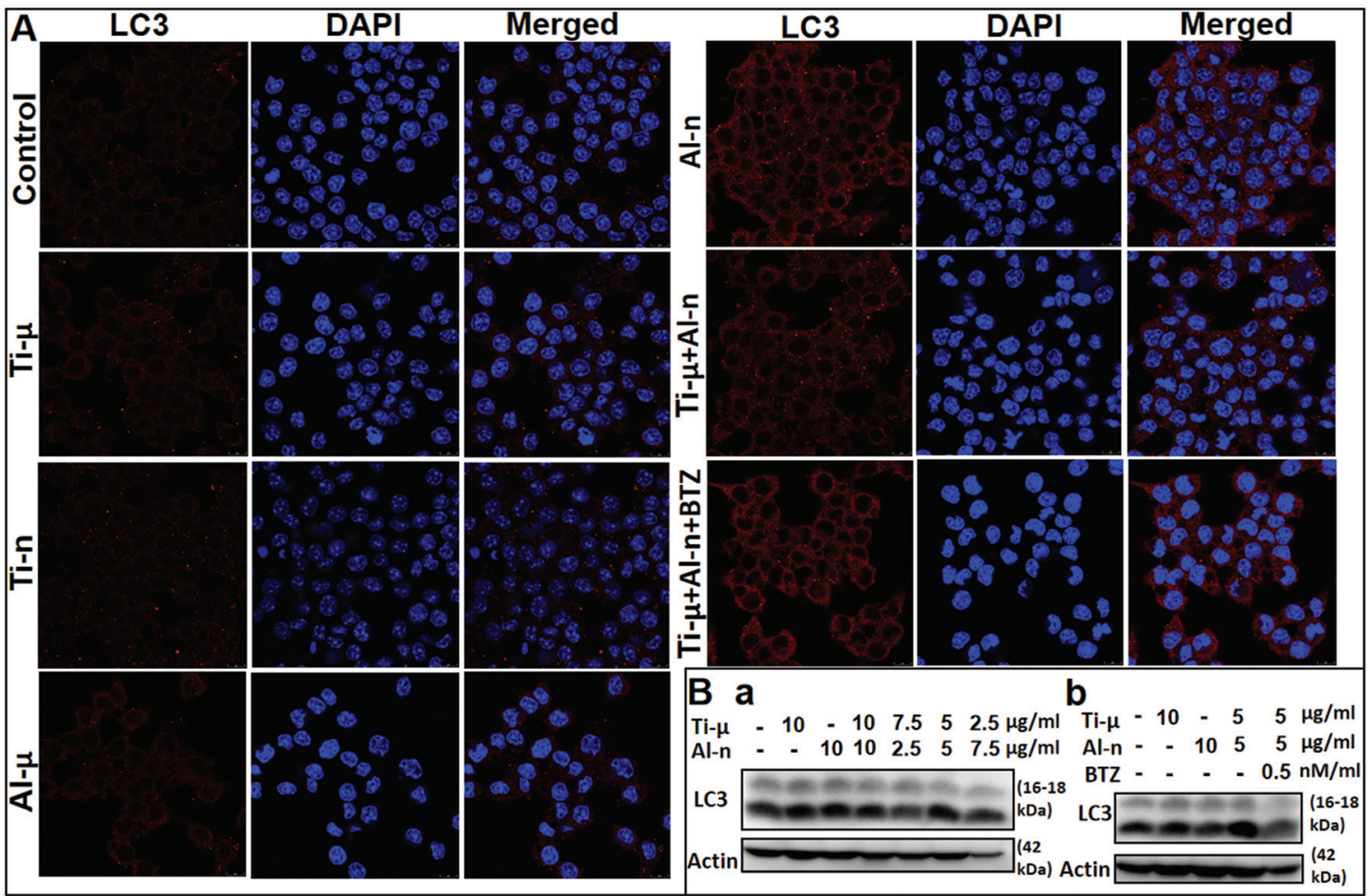

Fig. 4 The expression of LC3 in macrophages (the murine monocytic cell line RAW264.7). A: RAW264.7 cells were challenged with different size particles of $\mathrm{Ti}$ and $\mathrm{Al}$ for 3 days and were tested by immunofluorescence assays. (Group: control, $\mathrm{Ti}-\mu\left(10 \mu \mathrm{g} \mathrm{ml} \mathrm{m}^{-1} \mathrm{of} \mathrm{Ti- \mu} \mathrm{particles),} \mathrm{Al- \mu}\right.$ (10 $\mu \mathrm{g} \mathrm{ml}^{-1}$ of Al- $\mu$ particles), Ti-n (10 $\mu \mathrm{g} \mathrm{ml}^{-1}$ of Ti-n particles), Al-n (10 $\mu \mathrm{g} \mathrm{ml}^{-1}$ of Al-n particles), Ti- $\mu+\mathrm{Al}-\mathrm{n}\left(10 \mu \mathrm{g} \mathrm{ml} l^{-1}\right.$ of Ti- $\mu$ mixed with Al-n, Ti- $\mu: \mathrm{Al}-\mathrm{n}=1: 1)$ and Ti- $\mu$ + Al-n + BTZ $\left(10 \mu \mathrm{g} \mathrm{ml}^{-1}\right.$ of Ti- $\mu$ mixed with Al-n and $0.5 \mu \mathrm{mol} \mathrm{ml}^{-1} \mathrm{BTZ}, \mathrm{Ti}-\mu:$ Al-n = 1:1). B: Western Blot analysis of whole cell lysatesderived from RAW264.7 cells incubated with or without particle. (B-a group: control, $10 \mu \mathrm{g} \mathrm{ml}^{-1}$ of Ti- $\mu$ particles, $10 \mu \mathrm{g} \mathrm{ml}{ }^{-1}$ of Al-n particles, $20 \mu \mathrm{g} \mathrm{ml}^{-1}$ of Ti- $\mu$ mixed with Al-n (Ti- $\left.\mu: \mathrm{Al}-\mathrm{n}=1: 1\right), 10 \mu \mathrm{g} \mathrm{ml}^{-1}$ of Ti- $\mu$ mixed with Al-n (Ti- $\left.\mu: \mathrm{Al}-\mathrm{n}=3: 1\right), 10 \mu \mathrm{g} \mathrm{ml} \mathrm{l}^{-1}$ of Ti- $\mu$ mixed with Al-n (Ti- $\mu: \mathrm{Al}-\mathrm{n}=1: 1), 10 \mu \mathrm{g} \mathrm{ml}^{-1}$ of Ti- $\mu$ mixed with Al-n (Ti- $\left.\mu: \mathrm{Al}-\mathrm{n}=1: 3\right)$, and $10 \mu \mathrm{g} \mathrm{ml}^{-1}$ of Ti- $\mu$ mixed with Al-n and $0.5 \mu \mathrm{mol} \mathrm{ml}^{-1} \mathrm{BTZ}$ (Ti- $\mu$ : Al-n = 1:1); B-b group: control, $10 \mu \mathrm{g} \mathrm{ml}^{-1}$ of Ti- $\mu$ particles, $10 \mu \mathrm{g} \mathrm{ml}^{-1}$ of Al-n particles, $10 \mu \mathrm{g} \mathrm{ml}^{-1}$ of Ti- $\mu$ mixed with Al-n (Ti- $\mu: \mathrm{Al}-\mathrm{n}=1: 1$ ), and $10 \mu \mathrm{g} \mathrm{ml}^{-1}$ of Ti- $\mu$ mixed with Al-n and $0.5 \mu \mathrm{mol} \mathrm{ml^{-1 }} \mathrm{BTZ}(\mathrm{Ti}-\mu: \mathrm{Al}-\mathrm{n}=1: 1)$.

cal interaction of Ti- $\mu$ and Al-n occurred via the activator of the NF- $\mathrm{BB}$ signaling pathway, while $\beta$-TRCP was a key regulator of the NF- $\mathrm{B}$ signaling pathway.

CYLD is one of the most well-researched deubiquitinating enzymes, which inhibited the NF- $\kappa \mathrm{B}$ signal pathway. In this study, the expression of CYLD in single particle groups was activated at a higher level in the Al-n group than the Ti- $\mu$ group (Fig. 5C). In the mixture groups, when the Ti- $\mu$ and Al-n particles mixture was at a higher amount $\left(20 \mu \mathrm{g} \mathrm{ml} \mathrm{m}^{-1}\right)$, it triggered the overexpression of CYLD. Furthermore, the TNF- $\alpha$ and $\beta$-TRCP exhibited a higher expression level in the Ti- $\mu$ group (Fig. 5C and $\mathrm{F}$ ). When the concentration of $\mathrm{Al}-\mathrm{n}$ increased in the mixture, the inflammation was at a lower level with a low level of CYLD. When the mixture group was co-cultured with BTZ, the BTZ could block the activity of the NF- $\kappa$ B pathway and the expression of CYLD was absolutely weak. It indicated that when the inflammation was in a high level, it could trigger the feedback regulation of CYLD in the NF-kB pathway. All of these results indicated that $\mathrm{Al}-\mathrm{n}$ particles prevented the macrophage M1 polarization-related inflammation induced by $\mathrm{Ti}-\mu$ particles via preventing the activation of the NF- $\mathrm{KB}$ signaling pathway. These results agree with Fig. 4. Al-n evoked LC-3 expression, and autophage activation could play the function in the efficient clearance of dying cells by macrophages, and serves in dampening the M1 polarization-related pro-inflammatory responses.

3.6 Al-n particle and BTZ prevented inflammation and tissue broken in soft tissue induced by $\mathrm{Ti}-\mu$ particle

Compared with the Al-n groups, the in vivo study also showed that the $\mathrm{Ti}-\mu$ group was more toxic, as the in vitro experiments showed. The HE staining assay exhibited more serious damage to the tissue structure in the $\mathrm{Ti}-\mu$ group compared to other groups. For example, the integrity of the epithelium was broken, and the connective tissue fibers were disordered (Fig. 6A). HE staining also revealed that the obvious inflammatory infiltration of lymphocytes and macrophages, as well as multinucleated osteoclasts, existed in the soft tissue of the surgical area in the granule - stimulated mice, especially in the Ti- $\mu$ group. Al-n and BTZ could alleviate the toxicity of Ti- $\mu$.

\subsection{Al-n and BTZ blocked the activation of NF-к $\beta$ signaling induced by the Ti- $\mu$ particle in vivo}

Compared with Ti- $\mu$, Al-n and BTZ could decrease the expression of inflammatory cytokines in the particle mixing group (Fig. 6B). RANKL could preserve the survival of mature osteoclasts and restore their bone resorptive functions. In our 
A
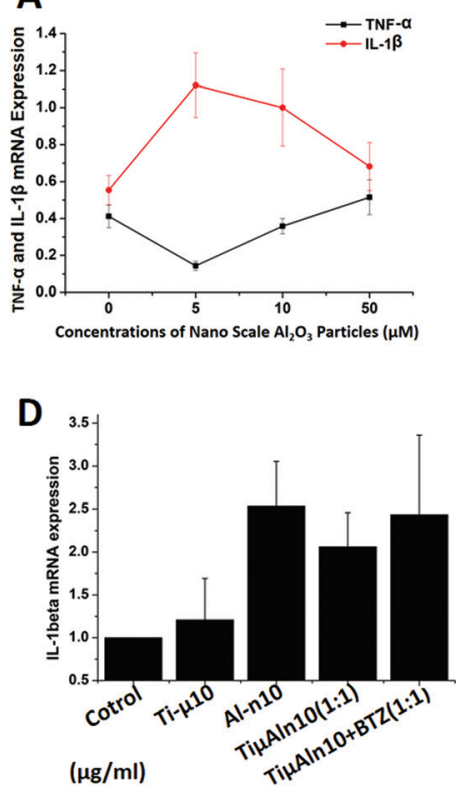

B

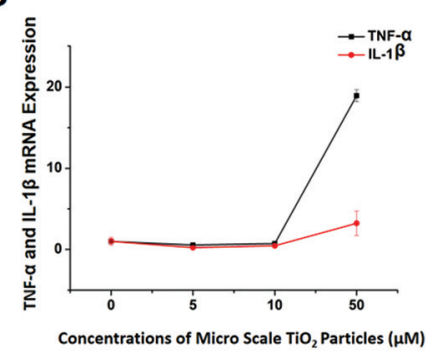

E

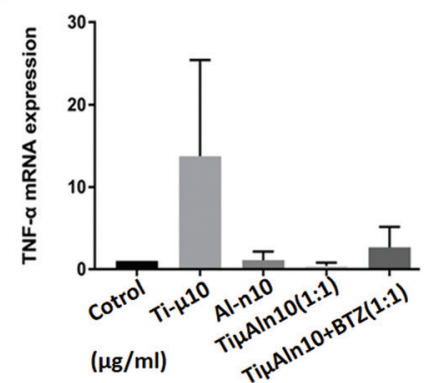

C

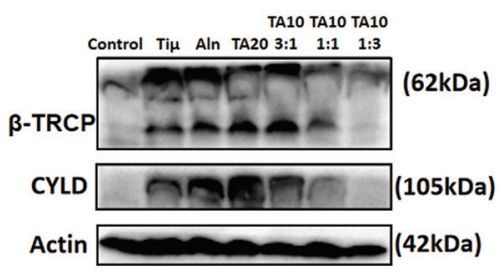

F

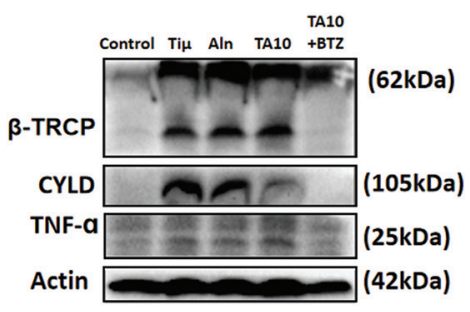

Fig. $5 \mathrm{Al}-\mathrm{n}$ and BTZ prevented the inflammation induced by Ti- $\mu$ via inhibiting the activation of the NF- $\mathrm{B}$ signaling pathway. A: A mRNA screen of TNF- $\alpha$ and IL-1 $\beta$ expression of macrophages under the stimulation of different concentrations of Al- $n$ particles. B: A mRNA screen of TNF- $\alpha$ and IL-1 $\beta$ expression of macrophages under the stimulation of different concentrations of Ti- $\mu$ particles. C: WB (Western Blot) analysis of whole cell lysates (WCL) derived from RAW264.7 cells incubated with or without particles (Groups: control, Ti- $\mu$ (10 $\mu \mathrm{g} \mathrm{ml}^{-1}$ of Ti- $\mu$ particles), Al-n (10 $\mu \mathrm{g} \mathrm{ml}{ }^{-1}$ of Al-n particles), $3: 1$ (10 $\mu \mathrm{g} \mathrm{ml}^{-1}$ of Ti- $\mu$ mixed with Al-n, Ti- $\left.\mu: \mathrm{Al}-\mathrm{n}=3: 1\right), 1: 1\left(10 \mu \mathrm{g} \mathrm{ml}^{-1}\right.$ of Ti- $\mu$ mixed with Al-n, Ti- $\left.\mu: \mathrm{Al}-\mathrm{n}=1: 1\right), 1: 3(10 \mu \mathrm{g}$ $\mathrm{ml}^{-1}$ of Ti- $\mu$ mixed with Al-n, Ti- $\mu:$ Al- $\left.n=1: 3\right)$, and TA20 $\left(20 \mu \mathrm{gl}^{-1}\right.$ of Ti- $\mu$ mixed with Al-n, Ti- $\mu:$ Al- $\left.n=1: 1\right)$ for 72 hours. NF- $\kappa B$ activation was assessed by examining the expression of $\beta$-TRCP, and CYLD was tested. D and E: The expression of IL- $1 \beta$ and TNF- $\alpha$ after exposure to Ti- $\mu$ and Al-n particles. (Groups: control, Ti- $\mu\left(10 \mu \mathrm{g} \mathrm{ml}^{-1}\right.$ of Ti- $\mu$ particles), Al-n $\left(10 \mu \mathrm{g} \mathrm{ml}^{-1}\right.$ of Al-n particles), $10 \mu \mathrm{g} \mathrm{ml}{ }^{-1}$ of Ti- $\mu$ mixed with Al-n (Ti- $\left.\mu: \mathrm{Al}-\mathrm{n}=1: 1\right)$,

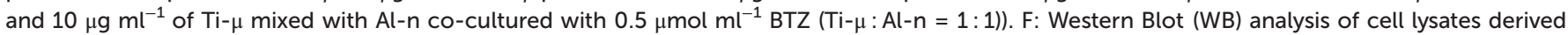
from RAW264.7 cells incubated with or without particles and BTZ for 72 hours (Groups: Control, Ti- $\mu 10$ (10 $\mu$ g ml ${ }^{-1}$ of Ti- $\mu$ particles), Al-n 10 (10 $\mu \mathrm{g}$ $\mathrm{ml}^{-1}$ of Al-n particles), TA10 $\left(10 \mu \mathrm{g} \mathrm{ml}^{-1}\right.$ of Ti- $\mu$ mixed with Al-n $\left.(\mathrm{Ti}-\mu: \mathrm{Al}-\mathrm{n}=1: 1)\right)$, and TA10 + BTZ $\left(10 \mu \mathrm{g} \mathrm{ml}{ }^{-1}\right.$ of Ti- $\mu$ mixed with Al-n co-cultured with $\left.\left.0.5 \mu \mathrm{mol} \mathrm{ml}{ }^{-1} \mathrm{BTZ}(\mathrm{Ti}-\mu: \mathrm{Al}-\mathrm{n}=1: 1)\right)\right)$. WCL was analyzed with antibodies against TRCP, CYLD, TNF- $\alpha$ and $\beta$-actin.

animal models (Fig. 6B), the presence of $\mathrm{Ti}-\mu$ granules resulted in inflammation and tissue disorder. RANKL exhibited a higher expression in the $\mathrm{Ti}-\mu$ group compared with the $\mathrm{Al}-\mathrm{n}$ group. In the mixture group, RANKL showed a lower level of activation compared with the Ti- $\mu$ group. Again, BTZ could block its expression in the mixture group. In addition, the toxicity of $\mathrm{Ti}-\mu$ could be inferred from the higher expression of Casepase 3 in the Ti- $\mu$ group compared with the other groups. Al-n could decrease the toxicity in the mixture group, and BTZ showed the same effect as Al-n. The inflammatory cytokine, such as IL-6, also expressed at a lower level in the control and $\mathrm{Al}-\mathrm{n}$ groups, while they had a higher expression level in the Ti- $\mu$ group. We could get the conclusion again that these bone resorptionrelated signaling pathway and inflammatory factors were evoked by Ti- $\mu$ particles, and prevented by Al-n particles and BTZ.

\subsection{Aseptic bone loosening induced by $\mathrm{Ti}-\mu$ was prevented by} the Al-n particle and administrated BTZ in the mouse model

Bone resorption was increased by $\mathrm{Ti}-\mu$ particles and prevented by Al-n particles and BTZ, which was confirmed by CT analysis (Fig. 7). As the micro-CT data (Fig. 7A-C) show, the trabecular spacing (SP) increased significantly in the $\mathrm{Ti}-\mu$ group compared with the other group in a quantitative analysis (Fig. 7A) $(p<0.01)$. The SP decreased in the Al-n group, the mixture group and the BTZ administration group $(p<0.01)$. The trabecular thickness (Th) showed more serious damage in the Ti- $\mu$ group compared with the other groups and increased in the Al-n group, mixture group and BTZ administration group ( $p<$ 0.01). The BV/TV was significantly higher in the Al-n group than the $\mathrm{Ti}-\mu$ group. BV/TV decreased in the $\mathrm{Ti}-\mu$ group compared to the control group, but this indicator significantly increased in the $\mathrm{Ti}-\mu+\mathrm{Al}-\mathrm{n}$ group. As the result shows above (Fig. 2), Ti- $\mu$ induced the macrophage apoptosis, and this aseptic bone loosening induced by $\mathrm{Ti}-\mu$ could be due to the reduced phagocytosis of the macrophages and the imbalance of the osteoblast and osteoclast around the implantation, and the response of the osteoblast was in progress in our other project. All of these agreed with the soft tissue results and in vitro results, and could be obviously observed in the $3 \mathrm{D}$ reconstruction version (Fig. 7B and C).

\section{Discussion}

The implant particle residual causes harmful effects and diseases, such as PD, while it is inevitable to apply Ti as a bioma- 

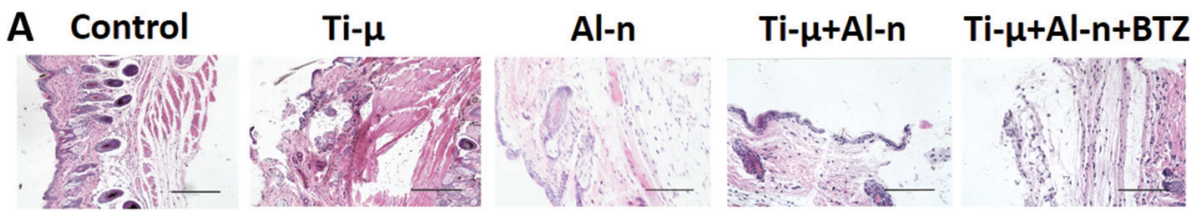

B
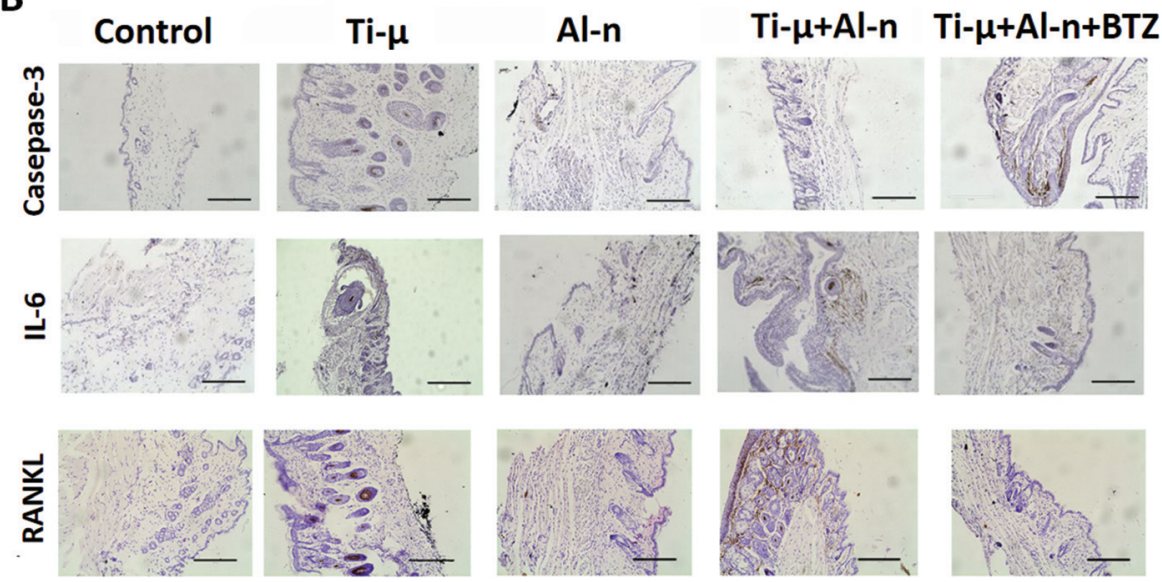

Fig. 6 Al-n particle and BTZ prevented inflammation and tissue broken in soft tissue induced by Ti- $\mu$ particles via blocking the activation of NF- $\kappa \beta$ signaling. A: HE of soft tissue harvested from C57BL/6 mice in groups: control; Ti- $\mu$ : $10 \mathrm{mg}$ of Ti- $\mu$ particles; Al-n: $10 \mathrm{mg}$ of Al-n particles; $10 \mathrm{mg}$ of $\mathrm{Ti}-\mu$ mixed with Al-n, Ti- $\mu: \mathrm{Al}-\mathrm{n}=1: 1 ; 10 \mathrm{mg}$ of Ti- $\mu$ mixed with Al-n co-cultured with $120 \mu \mathrm{L} \mathrm{BTZ}$ every two days, Ti- $\mu: \mathrm{Al}-\mathrm{n}=1: 1 .(\mathrm{Bar}=0.1 \mathrm{~mm})$. B: Immunohistochemistry of soft tissue samples that were harvested from C57BL/6 mice (Groups: control, Ti- $\mu$ (10 mg of Ti- $\mu$ particles), Al-n (10 mg of Al-n particles), $10 \mathrm{mg}$ of Ti- $\mu$ mixed with Al-n (Ti- $\mu$ : Al- $n=1: 1$ ), and $10 \mathrm{mg}$ of Ti- $\mu$ mixed with Al-n administrated with $120 \mu \mathrm{L}$ BTZ locally every two days $(\mathrm{Ti}-\mu: \mathrm{Al}-\mathrm{n}=1: 1)$ ) were tested with antibodies: Casepase-3, IL-6, RANKL. (Bar $=0.1 \mathrm{~mm})$.

terial considering its outstanding mechanical property. ${ }^{1-4}$ In this study, after a biological screen of different particles (Fig. 1), we found that Al-n particles could prevent the toxicity induced by Ti- $\mu$ particles (Fig. 2 and 3). In further studies, our results showed that Al-n induced an obvious LC3-Associated Phagocytosis (LAP) process, rather than Ti- $\mu$ (Fig. 4). Al-n particles activated LAP and IL-1 $\beta$ expression and blocked the NF$\kappa B$ signaling activation, which resulted in decreasing the inflammatory factor expression and preventing macrophage M1 polarization-related inflammation (Fig. 4 and 5), and prevented soft tissue inflammation and bone loss induced by Ti- $\mu$ in the micro-CT, hematoxylin-eosin (HE) and immunohistochemistry experiments in vivo (Fig. 6 and 7). The BTZ exhibited a therapeutic effectiveness for PD in vitro and in vivo (Fig. 2-7).

Wear particles could cause irreversible aseptic prosthesis loosening, and play a pathological role in the occurrence and development of periprosthetic osteolysis. ${ }^{5,7,16,39}$ According to the American Society of Testing Materials (ASTM), particles should be categorized to the micrometer $(1-10 \mu \mathrm{m})$, submicrometer $(0.2-1 \mu \mathrm{m})$ and nanometer $(0.01-0.2 \mu \mathrm{m})$ scale, but its implant friction process, pro-inflammatory process and clinical analysis found that it is far more complicated than this. ${ }^{40}$ In the United States, more than more than 600000 knee arthroplasties and 285000 total hip arthroplasties (THA) are performed each year. ${ }^{41}$ Nowadays, different bearing surfaces are utilized in clinical practice, and could be classified into hard-on-hard surfaces and hard-on-soft surfaces, such as ceramic-on-ceramic, metal-on-metal, metal-on-ceramic, metal- on-polymer and other examples. ${ }^{41,42}$ The implant wear debris could be found in peri-implant tissues, and the diameter of wear particles are different from material to material, such as the microscale $(10 \mu \mathrm{m})$ and nanoparticles of the Ti alloy $(<50 \mathrm{~nm}),{ }^{3,43,44}$ microscale $(0.1-7 \quad \mu \mathrm{m})$ and nanoscale (5-90 nm) of ceramic particles, ${ }^{45-47}$ and microparticle and submicroparticles $(0.1-0.5 \mu \mathrm{m}, 1-10 \mu \mathrm{m}$, or even $100 \mu \mathrm{m})$ of polymers. ${ }^{48,49}$ So, the particles of different materials that could be found in the peri-implant tissue were not of the same size. In this study, we set a large and a small diameter for each material to cover a big range of scale for each material to represent the particles that could be found in the peri-implant tissue (Fig. 1).

In the global aging era, a further understanding of the biological interaction between particles for better implant design and drug therapy for those senior people who could not suffer from a secondary replacement surgery is the vital strategy to fight again particle disease. Most orthopedic implant failures are due to aseptic loosening caused by granular stimulation, and treatment options are mostly surgical revision. Studies are trying to understand the cellular and molecular biologic processes involved in the particle-pharmacy interaction of particles disease, and to find a potential therapy. ${ }^{7,8,50,51}$ With the flow-cytometric analysis, we performed biological screens, and they showed that $\mathrm{TiO}_{2}$ and UHMWPE were more toxic than $\mathrm{Al}_{2} \mathrm{O}_{3}$ particles (Fig. 2 and ESI Fig. $2 \dagger$ ).

Osteoclasts are the unique cells involved in bone resorption, which originate from the myeloid cells of the monocyte/ 

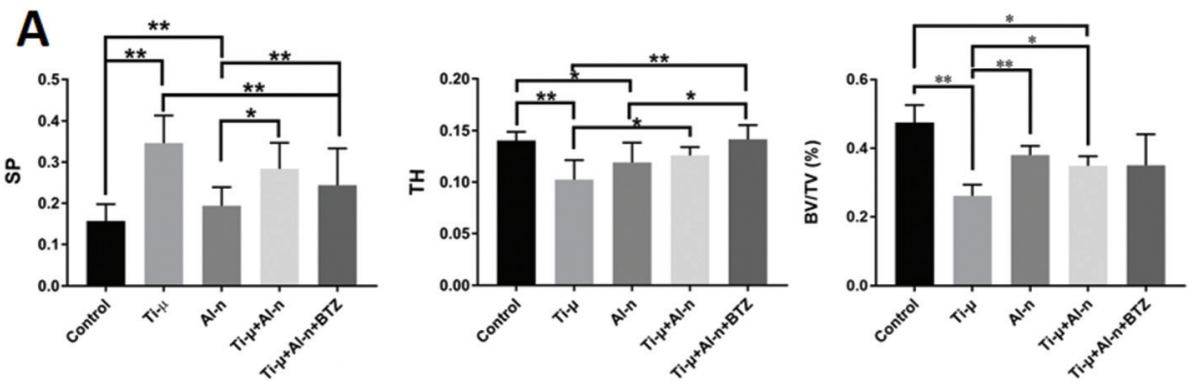

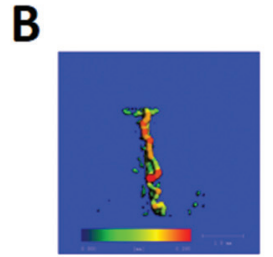

C
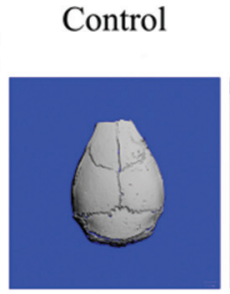

Control

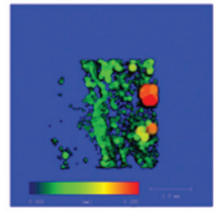

Ti- $\mu$

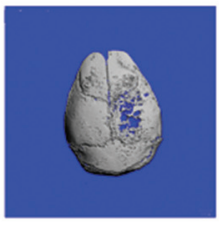

Ti- $\mu$

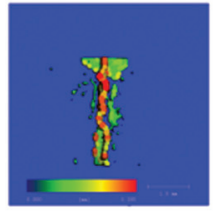

Al-n

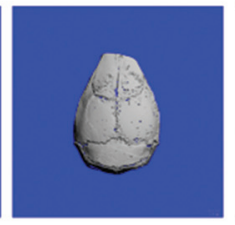

Al-n

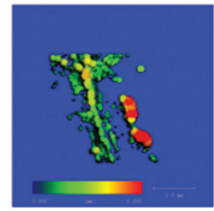

Ti- $\mu+A l-n$

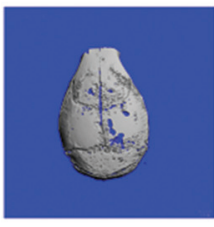

Ti- $\mu+$ Al-n $\quad$ Ti- $\mu+A l-n+B T Z$

Fig. 7 Aseptic bone loosening induced by Ti- $\mu$ was prevented by Al-n particles, and BTZ was administrated in mouse model. A: The trabecular thickness and porosity percentage in a region of interest (ROI) of $1.5 \times 1.5 \mathrm{~mm}$ in the surgical area of the cranium harvested from C57BL/6 mice (groups: control, Ti- $\mu$ (10 mg of Ti- $\mu$ particles), Al-n (10 mg of Al-n particles), $10 \mathrm{mg}$ of Ti- $\mu$ mixed with Al-n (Ti- $\mu: \mathrm{Al}-\mathrm{n}=1: 1)$, and $10 \mathrm{mg}$ of $\mathrm{Ti}-\mu$ mixed with Al-n administrated with $120 \mu \mathrm{L} \mathrm{BTZ} \mathrm{locally} \mathrm{every} \mathrm{two} \mathrm{days}(\mathrm{Ti}-\mu: \mathrm{Al}-\mathrm{n}=1: 1)$ ) were measured and statistical analysed. (* $P<0.05$ and $\left.{ }^{* *} P<0.01\right)$. B: 3D reconstruction of the porosity images of the ROI of $1.5 \times 1.5 \mathrm{~mm}$ in each group. C: 3D reconstruction of the mouse calvaria in each group. (SP: trabecular spacing, TH: trabecular thickness, BV/TV: bone volume/total volume).

macrophage lineage to maintain bone homeostasis. ${ }^{9-11}$ LC3associated phagocytosis (LAP) is a non-canonical autophage and an autophagosome-independent process. ${ }^{27,29}$ It has the function in the efficient clearance of dying cells by macrophages, and serves in dampening pro-inflammatory responses. Recently, it was reported that inhibition of autophagy significantly elevated the expression of NF-kB-dependent TNF $\alpha /$ IL-1 $\beta$ in S. aureus-infected macrophages, RAW264.7. ${ }^{30,31}$ However, the effect of the particle and biological interaction of different particles on the LAP were unclear. In our immunofluorescence assays, LC-3 expression was higher in the Al-n group and mixture group than the Ti- $\mu$ and control groups (Fig. 4). A flow cytometry experiment (Fig. 2) showed that Ti- $\mu$ induced a higher property of apoptosis and necrosis cells. LAP could inhibit the autoinflammatory response to dying cells. ${ }^{30}$ Our results indicated that there was a biological interaction among different particles. What is more, it suggested that Al-n activated LAP and efficiently engulfed the dying cells in macrophages, and prevented inflammation induced by Ti- $\mu$.

$\beta$-TRCP is a member of the F-box protein family and the SCF (Skpl-Cullinl-F-box type ubiquitin ligase) E3 key components. It is the activator of the NF-кB signaling pathway through recognition and ubiquitination of specific phosphory- lated substrates, such as IKB, thereby regulating the cell growth, differentiation, apoptosis and the occurrence of tumors. TNF- $\alpha$ is an important inflammatory factor in the NF$\kappa \mathrm{B}$ signaling pathway. ${ }^{51-53}$ TNF- $\alpha$ could significantly promote the M1 polarization of the macrophage, which is characterized by the expression of high levels of proinflammatory cytokines. In contrast, IL- $1 \beta$ is more likely to induce macrophage M2 polarization, which plays a function toward the anti-inflammatory responses. ${ }^{18,19,54}$ In this study, we verified that both micro- and nanoscale $\mathrm{TiO}_{2}$ particles induced a higher level of TNF- $\alpha$ compared with the IL- $1 \beta$ level. In contrast, $\mathrm{Al}_{2} \mathrm{O}_{3}$ evoked a higher level of IL-1 $\beta$ compared with the TNF- $\alpha$ level in a concentration-dependent manner (Fig. 5 and ESI Fig. $4 \dagger$ ).

CYLD is one of the most well-researched deubiquitinating enzymes that inhibits the NF- $\kappa$ B signal pathway. ${ }^{50,55,56}$ CYLD in single particle groups was activated at a higher level in the Al-n group than Ti- $\mu$ group (Fig. 5). This might contribute to the feedback effect of CYLD as an inhibitor of the NF-kB signaling pathway, and this feedback effect was first reported by our previous study. ${ }^{55}$ In the mixture groups, the feedback effect was confirmed wherein a higher amount $\left.(20 \mu \mathrm{g} \mathrm{ml})^{-1}\right)$ of the Ti- $\mu$ and Al-n particles mixture triggered the overexpression of CYLD (Fig. 5C). Furthermore, the TNF- $\alpha$ and $\beta$-TRCP exhibi- 
ted a higher expression level in the Ti- $\mu$ group (Fig. 5F). It suggested that when the concentration of Al-n increased in the mixture, the inflammation was at a lower level. The feedback effect could not be triggered, and the CYLD decreased in a concentration-depending manner of $\mathrm{Al}-\mathrm{n}$ in the mixture groups. All of these results indicated that Al-n activated the LAP and prevented the inflammation induced by $\mathrm{Ti}-\mu$ not only via activation of $\beta$-TRCP/NF- $\kappa \mathrm{B}$, but also via the inhibitor of CYLD/NF$\kappa \mathrm{B}$. When the inflammation was in a high level, the feedback circle of CYLD would work.

Recently, BTZ was considered as a therapy for inflammation and its dose-dependent manner was reported by studies. ${ }^{22,34}$ At a low dose, BTZ could prevent cells from apoptosis rather than induce cell apoptosis. Our previous study showed that BTZ inhibited inflammation of the periodontal ligament cell and periodontal tissues. ${ }^{32}$ In this study, while the knockdown and knockout macrophage cell line was too fragile to suffer drug cell line purification and particle stimulation, such as knockout $\beta$-TRCP cell line, BTZ was applied as a therapeutic drug and an inhibitor for the NF- $\mathrm{BB}$ signaling. BTZ and Al-n could effectively inhibit the cell apoptosis (Fig. 2 and 3), increased the cell viability weakened by $\mathrm{Ti}-\mu$ particles, evoked the autophage process and LC3 expression reduced by Ti- $\mu$ (Fig. 4), and attenuated the M1-related inflammatory expression induced by Ti- $\mu$ (Fig. 5). After cells were treated with BTZ, their $\beta$-TRCP and TNF- $\alpha$ expression decreased. It suggested that BTZ mainly prevented inflammation and apoptosis by inhibiting $\beta$-TRCP. In the mixture groups when the cells were under a low level of inflammation, the feedback loop of the CYLD effect was not fully activated (Fig. 5). All of these data indicated that Al-n particles prevented the macrophage M1 polarization-related inflammation induced by $\mathrm{Ti}-\mu$ particles via NF-кB signaling pathway.

It has been reported that after exposure to RANKL-RANK, the signaling pathway related to the bone resorption is activated, such as the NF- $\kappa$ B signaling pathway. ${ }^{50,57}$ RANKL could also preserve the survival of mature osteoclasts and restore their bone resorptive functions. In this study, the presence of Ti- $\mu$ granules resulted in inflammation tissue disorder (Fig. 6A) and bone resorption. This bone resorption-related signaling pathway and inflammatory factors were evoked by $\mathrm{Ti}-\mu$ particles, and prevented by Al-n particles and BTZ (Fig. 6B). The same result could be obtained by CT analysis (Fig. 7). With immunohistochemistry, we further found that Al-n and BTZ played a role through casepase 3 to prevent bone resorption induced by $\mathrm{Ti}-\mu$, which agreed with the phagocytosis phenomenon and cell fragments of lysis shown in Fig. 3.

It is inevitable to use the Ti alloy as a bulk implant material, a particle-enforced composite material, or a drug delivery material, considering its outstanding mechanical property. ${ }^{1,2}$ However, the particle toxicity released after longterm use is reported. In this manuscript, it is interesting and novel to find that Al-n particles induce LC3-Associated phagocytosis, which could play the function in the efficient clearance of dying cells by macrophages. It also serves in dampening M1 polarization-related pro-inflammatory responses and aseptic

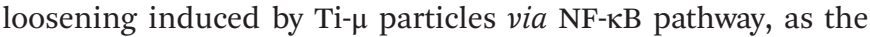
mimic mechanism shows (ESI Fig. 6†). So, the outstanding mechanic character and the potential toxicity of microscale $\mathrm{TiO}_{2}$ particles and the activating LAP character of nanoscale $\mathrm{Al}_{2} \mathrm{O}_{3}$ particles should both be considered in implant design and in the strategy of materials selection. When the mechanical components of the implant has a high requirement of mechanic character, the Ti alloy should be applied. When the mechanical components of the implant need a high requirement of biological character, the Al alloy should be proposed. Additionally, Bortezomib was a potential therapeutic drug for particle disease in senior patients, rather than joint replacement surgery.

\section{Conclusions}

The Ti- $\mu$ implant particle residual was more toxic than the Al-n implant particle residual. Al-n prevented particle disease induced by Ti- $\mu$ via evoking the LAP process, and blocking the activation of NF-kB pathway and macrophage M1 polarizationrelated inflammation. Al-n and BTZ could significantly reduce the inflammation and aseptic absorption induced by Ti- $\mu$ particles via occupying the inflammation receptor, blocking the cell toxicity, NF- $\kappa \mathrm{B}$ activation, M1 polarization-related inflammatory factors expression and apoptosis, and via initiating autophagy process. While Ti alloy implant is applied worldwide, its toxicity should be considered. The biological interaction of Ti- $\mu$ and Al-n in this study could be fully utilized during implant design, and Bortezomib should be a potential therapeutic drug for particle disease in senior patients rather than joint replacement surgery.

\section{Ethical statement}

All animal procedures were performed in accordance with the Guidelines for Care and Use of Laboratory Animals of Chongqing Medical University, and approved by the Animal Ethics Committee of Chongqing Medical University.

\section{Author contributions}

Prof. Xiaomian Wu contributed to the conceptualization; Prof. Xiaomian $\mathrm{Wu}$, Prof. Xiaolei $\mathrm{Hu}$, Prof. Ling $\mathrm{Xu}$, Prof. Jiao Huang, Prof. Feng Deng, and Prof. Ping Ji contributed to the resources, funding acquisition, project administration and supervision; Prof. Xiaomian Wu, Prof. Xiaolei $\mathrm{Hu}$, Xuewei $\mathrm{Fu}$, Prof. Ling Xu, Prof. Ping Ji, Prof. Feng Deng, Zhiwei Zhang, and Prof. Jiao Huang contributed to the methodology, data curation, investigation, software, formal analysis, original draft writing and writing - review; Prof. Xiaomian $\mathrm{Wu}$ and Prof. Xiaolei $\mathrm{Hu}$ contributed to the visualization, revision and writing - editing. 


\section{Conflicts of interest}

The authors declare no conflict of interests among the authors.

\section{Acknowledgements}

This research was supported by the National Natural Science Foundation of China (31400808), Natural Science Foundation of Chongqing, China (cstc2020jcyj-msxmX0321), and Overseas Returnees Innovation and Entrepreneurship Support Program of Chongqing (cx2019095) to Xiaomian Wu. This study was also supported by the National Natural Science Foundation of China (21402018, 81570979 and 31871464). We also thank Quangao Du for assistance with mRNA screening of inflammatory responses, Zhiqiang Yang for assistance with animal experiment, and Baoming Zhang for assistance with TEM and FTIR analyses.

\section{References}

$1 \mathrm{X} . \mathrm{Wu}$, et al., Nano-TiO2/PEEK bioactive composite as a bone substitute material: in vitro and in vivo studies, Int. J. Nanomed., 2012, 7, 1215-1225, DOI: 10.2147/ijn. s28101.

2 M.-T. Huang, et al., The potential of the three-dimensional printed titanium mesh implant for cranioplasty surgery applications: Biomechanical behaviors and surface properties, Mater. Sci. Eng., C, 2019, 97, 412-419, DOI: 10.1016/j.msec.2018.11.075.

3 M. Eger, et al., Mechanism and Prevention of Titanium Particle-Induced Inflammation and Osteolysis, Front. Immunol., 2018, 9, 2963-2963, DOI: 10.3389/fimmu.2018. 02963.

4 E. Bressan, et al., Metal Nanoparticles Released from Dental Implant Surfaces: Potential Contribution to Chronic Inflammation and Peri-Implant Bone Loss, Materials, 2019, 12, 2036, DOI: 10.3390/ma12122036.

5 L. Wang, et al., Protein phosphatase 2A as a new target for downregulating osteoclastogenesis and alleviating titanium particle-induced bone resorption, Acta Biomater., 2018, 73, 488-499, DOI: 10.1016/j.actbio.2018.04.013.

6 J. J. Cherian, J. J. Jauregui, S. Banerjee, T. Pierce and M. A. Mont, What Host Factors Affect Aseptic Loosening After THA and TKA?, Clin. Orthop. Relat. Res., 2015, 473, 2700-2709, DOI: 10.1007/s11999-015-4220-2.

7 G. Luo, et al., Resveratrol Protects against Titanium Particle-Induced Aseptic Loosening Through Reduction of Oxidative Stress and Inactivation of NF- $\mathrm{BB}$, Inflammation, 2016, 39, 775-785, DOI: 10.1007/s10753-016-0306-6.

8 Z. Zhang, et al., Nanosized Alumina Particle and Proteasome Inhibitor Bortezomib Prevented inflammation and Osteolysis Induced by Titanium Particle via Autophagy and NF-kB Signaling, Sci. Rep., 2020, 10, 5562, DOI: 10.1038/s41598-020-62254-x.
9 M. M. Weivoda, et al., Identification of osteoclast-osteoblast coupling factors in humans reveals links between bone and energy metabolism, Nat. Commun., 2020, 11, 87-87, DOI: 10.1038/s41467-019-14003-6.

10 N. Dirckx, M. C. Moorer, T. L. Clemens and R. C. Riddle, The role of osteoblasts in energy homeostasis, Nat. Rev. Endocrinol., 2019, 15, 651-665, DOI: 10.1038/s41574-019-0246-y.

11 Y. Yahara, et al., Erythromyeloid progenitors give rise to a population of osteoclasts that contribute to bone homeostasis and repair, Nat. Cell Biol., 2020, 22, 49-59, DOI: 10.1038/s41556-019-0437-8.

12 Y. Jiang, T. Jia, W. Gong, P. H. Wooley and S. Y. Yang, Effects of Ti, PMMA, UHMWPE, and Co-Cr wear particles on differentiation and functions of bone marrow stromal cells, J. Biomed. Mater. Res., Part A, 2013, 101, 2817-2825, DOI: $10.1002 / \mathrm{jbm} . \mathrm{a} .34595$.

13 Z. Deng, et al., The metal nanoparticle-induced inflammatory response is regulated by SIRT1 through NF-kappaB deacetylation in aseptic loosening, Int. J. Nanomed., 2017, 12, 3617-3636, DOI: 10.2147/IJN.S124661.

14 Y. Yamanaka, K. Karuppaiah and Y. Abu-Amer, Polyubiquitination events mediate polymethylmethacrylate (PMMA) particle activation of NF-kappaB pathway, J. Biol. Chem., 2011, 286, 23735-23741, DOI: 10.1074/jbc.M111.223669.

15 G. A. Obando-Pereda, L. Fischer and D. R. Stach-Machado, Titanium and zirconia particle-induced pro-inflammatory gene expression in cultured macrophages and osteolysis, inflammatory hyperalgesia and edema in vivo, Life Sci., 2014, 97, 96-106, DOI: 10.1016/j.lfs.2013.11.008.

16 S. B. Goodman, et al., Novel biological strategies for treatment of wear particle-induced periprosthetic osteolysis of orthopaedic implants for joint replacement, J. R. Soc., Interface, 2014, 11, 20130962, DOI: 10.1098/rsif.2013.0962.

17 T. Cheng, et al., Transforming growth factor-beta activated kinase 1 signaling pathways regulate TNF-alpha production by titanium alloy particles in RAW 264.7 cells, J. Biomed. Mater. Res., Part A, 2010, 93, 1493-1499, DOI: 10.1002/jbm. a.32618.

18 R. Batra, et al., IL-1 $\beta$ (Interleukin-1 $\beta$ ) and TNF- $\alpha$ (Tumor Necrosis Factor- $\alpha$ ) Impact Abdominal Aortic Aneurysm Formation by Differential Effects on Macrophage Polarization, Arterioscler., Thromb., Vasc. Biol., 2018, 38, 457-463, DOI: 10.1161/atvbaha.117.310333.

19 A. Sica and A. Mantovani, Macrophage plasticity and polarization: in vivo veritas, J. Clin. Invest., 2012, 122, 787-795, DOI: $10.1172 /$ jci59643.

20 S. C. Sun, CYLD: a tumor suppressor deubiquitinase regulating NF-kappaB activation and diverse biological processes, Cell Death Differ., 2010, 17, 25-34, DOI: 10.1038/ cdd.2009.43.

$21 \mathrm{X} . \mathrm{Wu}$, et al., SCF $\beta$-TRCP regulates osteoclastogenesis via promoting CYLD ubiquitination, Oncotarget, 2014, 5, 42114221, DOI: 10.18632/oncotarget.1971.

22 L. Jiang, et al., The Proteasome Inhibitor Bortezomib Inhibits Inflammatory Response of Periodontal Ligament Cells and Ameliorates Experimental Periodontitis in Rats, 
J. Periodontol., 2017, 88, 473-483, DOI: 10.1902/ jop.2016.160396.

23 Y. Williams-Bey, C. Boularan, A. Vural, N.-N. Huang, I.Y. Hwang, et al., Omega-3 Free Fatty Acids Suppress Macrophage Inflammasome Activation by Inhibiting NF- $\mathrm{B}$ Activation and Enhancing Autophagy, PLoS One, 2014, 9(6), e97957, DOI: 10.1371/journal.pone.0097957.

24 E. Jimi, N. Takakura, F. Hiura, I. Nakamura and S. HirataTsuchiya, The Role of NF- $\kappa$ B in Physiological Bone Development and Inflammatory Bone Diseases: Is NF- $\mathrm{B}$ Inhibition "Killing Two Birds with One Stone"?, Cells, 2019, 8, E1636, DOI: 10.3390/cells8121636.

25 Z. Liu, et al., A NIK-SIX signalling axis controls inflammation by targeted silencing of non-canonical NF- $\kappa \mathrm{B}$, Nature, 2019, 568, 249-253, DOI: 10.1038/s41586-019-1041-6.

26 A. Kumar, et al., Platelet-rich fibrin/biphasic calcium phosphate impairs osteoclast differentiation and promotes apoptosis by the intrinsic mitochondrial pathway in chronic periodontitis, J. Periodontol., 2019, 90, 61-71, DOI: 10.1002/JPER.17-0306.

27 B. L. Heckmann, et al., LC3-Associated Endocytosis Facilitates $\beta$-Amyloid Clearance and Mitigates Neurodegeneration in Murine Alzheimer's Disease, Cell, 2019, 178, 536-551, DOI: 10.1016/j.cell.2019.05.056.

28 J. Martinez, et al., Microtubule-associated protein 1 light chain 3 alpha (LC3)-associated phagocytosis is required for the efficient clearance of dead cells, Proc. Natl. Acad. Sci. U. S. A., 2011, 108, 17396-17401, DOI: 10.1073/ pnas.1113421108.

29 B. L. Heckmann, E. Boada-Romero, L. D. Cunha, J. Magne and D. R. Green, LC3-Associated Phagocytosis and Inflammation, J. Mol. Biol., 2017, 429, 3561-3576, DOI: 10.1016/j.jmb.2017.08.012.

30 J. Martinez, et al., Noncanonical autophagy inhibits the autoinflammatory, lupus-like response to dying cells, Nature, 2016, 533, 115-119, DOI: 10.1038/nature17950.

31 Y. Lv, L. Fang, P. Ding and R. Liu, PI3 K/Akt-Beclin1 signaling pathway positively regulates phagocytosis and negatively mediates NF-кB-dependent inflammation in Staphylococcus aureus-infected macrophages, Biochem. Biophys. Res. Commun., 2019, 510, 284-289, DOI: 10.1016/j. bbrc.2019.01.091.

32 P. Koulouvaris, et al., Expression profiling reveals alternative macrophage activation and impaired osteogenesis in periprosthetic osteolysis, J. Orthop. Res., 2008, 26, 106-116, DOI: $10.1002 /$ jor.20486.

33 S. Meiners, A. Ludwig, V. Stangl and K. Stangl, Proteasome inhibitors: poisons and remedies, Med. Res. Rev., 2008, 28, 309-327, DOI: 10.1002/med.20111.

34 L.-H. Hu, et al., Bortezomib protects against dextran sulfate sodium-induced ulcerative colitis in mice, Mol. Med. Rep., 2017, 15, 4093-4099, DOI: 10.3892/mmr.2017.6524.

35 S. B. Goodman, T. Ma, R. Chiu, R. Ramachandran and R. L. Smith, Effects of orthopaedic wear particles on osteoprogenitor cells, Biomaterials, 2006, 27, 6096-6101, DOI: 10.1016/j.biomaterials.2006.08.023.
36 I. A. Mudunkotuwa and V. H. Grassian, Histidine adsorption on $\mathrm{TiO} 2$ nanoparticles: an integrated spectroscopic, thermodynamic, and molecular-based approach toward understanding nano-bio interactions, Langmuir, 2014, 30, 8751-8760, DOI: 10.1021/la500722n.

37 A. Rajeshwari, et al., Cytotoxicity of aluminum oxide nanoparticles on Allium cepa root tip-effects of oxidative stress generation and biouptake, Environ. Sci. Pollut. Res. Int., 2015, 22, 11057-11066, DOI: 10.1007/s11356-015-4355-4.

38 R. Ortiz-Hernández, et al., Advances in the Processing of UHMWPE-TiO(2) to Manufacture Medical Prostheses via SPIF, Polymers(Basel), 2019, 11, 1-14, DOI: 10.3390/ polym11122022.

39 S. Landgraeber, et al., Adiponectin attenuates osteolysis in aseptic loosening of total hip replacements, Acta Biomater., 2014, 10, 384-393, DOI: 10.1016/j.actbio.2013.08.031.

40 S. Saha and M. Musib, Fractionation and characterization of particles simulating wear of total joint replacement (TJR) following ASTM standards, J. Long-Term Eff. Med. Implants, 2011, 21, 79-92, DOI: 10.1615/jlongtermeffmedimplants.v21.i1.70.

41 D. Bitar and J. Parvizi, Biological response to prosthetic debris, World J. Orthop., 2015, 6, 172-189, DOI: 10.5312/ wjo.v6.i2.172.

42 S. B. Goodman, J. Gallo, E. Gibon and M. Takagi, Diagnosis and management of implant debris-associated inflammation, Expert Rev. Med. Devices, 2020, 17, 41-56, DOI: 10.1080/17434440.2020.1702024.

43 J. Soto-Alvaredo, et al., Evaluation of the biological effect of Ti generated debris from metal implants: ions and nanoparticles, Metallomics: Integr. Biometal Sci., 2014, 6, 17021708, DOI: 10.1039/c4mt00133h.

44 X. Mao, X. Pan, X. Peng, T. Cheng and X. Zhang, Inhibition of titanium particle-induced inflammation by the proteasome inhibitor bortezomib in murine macrophage-like RAW 264.7 cells, Inflammation, 2012, 35, 1411-1418, DOI: 10.1007/s10753-012-9454-5.

45 G. Thrivikraman, G. Madras and B. Basu, In vitro/In vivo assessment and mechanisms of toxicity of bioceramic materials and its wear particulates, $R S C A d v$., 2014, 4, 12763, DOI: 10.1039/c3ra44483j.

46 S. Kargozar, et al., Biomedical applications of nanoceria: new roles for an old player, Nanomedicine, 2018, 13, 30513069, DOI: 10.2217/nnm-2018-0189.

47 S. Najeeb, et al., Modifications in Glass Ionomer Cements: Nano-Sized Fillers and Bioactive Nanoceramics, Int. J. Mol. Sci., 2016, 17, 1-14, DOI: 10.3390/ijms17071134.

48 J. I. Pearl, et al., Role of the Toll-like receptor pathway in the recognition of orthopedic implant wear-debris particles, Biomaterials, 2011, 32, 5535-5542, DOI: 10.1016/j. biomaterials.2011.04.046.

49 M. K. Musib, Response to Ultra-high Molecular Weight Polyethylene Particles, Am. J. Biomed. Eng., 2012, 1, 7-12, DOI: 10.5923/j.ajbe.20110101.02.

50 J. Cheng, et al., Interleukin-4 inhibits RANKL-induced NFATc1 expression via STAT6: a novel mechanism mediat- 
ing its blockade of osteoclastogenesis, J. Cell. Biochem., 2011, 112, 3385-3392, DOI: 10.1002/jcb.23269.

51 D. Li, et al., The inhibition of RANKL expression in fibroblasts attenuate CoCr particles induced aseptic prosthesis loosening via the MyD88-independent TLR signaling pathway, Biochem. Biophys. Res. Commun., 2018, 503, 11151122, DOI: 10.1016/j.bbrc.2018.06.128.

52 S.-C. Sun, Non-canonical NF-кB signaling pathway, Cell Res., 2011, 21, 71-85, DOI: 10.1038/cr.2010.177.

53 S. Schütze, K. Wiegmann, T. Machleidt and M. Krönke, TNF-induced activation of NF-kappa B, Immunobiology, 1995, 193, 193-203, DOI: 10.1016/s0171-2985(11)80543-7.

54 S. Taratummarat, et al., Gold nanoparticles attenuates bacterial sepsis in cecal ligation and puncture mouse model through the induction of M2 macrophage polarization, BMC Microbiol., 2018, 18, 85, DOI: 10.1186/s12866-0181227-3.

$55 \mathrm{X} . \mathrm{Wu}$, et al., SCF $\beta$-TRCP regulates osteoclastogenesis via promoting CYLD ubiquitination, Oncotarget, 2014, 5, 42114221, DOI: 10.18632/oncotarget.1971.

56 Y. Y. Li, et al., Exome and genome sequencing of nasopharynx cancer identifies NF- $\mathrm{BB}$ pathway activating mutations, Nat. Commun., 2017, 8, 14121-14121, DOI: 10.1038/ ncomms14121.

57 S. G. Romeo, et al., Endothelial proteolytic activity and interaction with non-resorbing osteoclasts mediate bone elongation, Nat. Cell Biol., 2019, 21, 430-441, DOI: 10.1038/ s41556-019-0304-7. 